\title{
Deciphering metal-induced oxidative damages on glycated albumin structure and function
}

\author{
Jennifer Baraka-Vidot ${ }^{\mathrm{a}, 1}$, Giovanna Navarra ${ }^{\mathrm{b}, *, 1}$, Maurizio Leone ${ }^{\mathrm{b}, \mathrm{c}}$, Emmanuel Bourdon ${ }^{\mathrm{a}}$, \\ Valeria Militello $^{\mathrm{b}, \mathrm{c}}$, Philippe Rondeau ${ }^{\mathrm{a}, * *}$

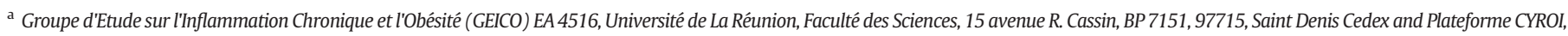 \\ 2 Rue Maxime Rivière, BP 80 005, 97491 Sainte Clotilde Cedex, Reunion Island, France \\ ${ }^{\mathrm{b}}$ Università di Palermo, Dipartimento di Fisica e Chimica, Via Archirafi 36, Palermo, Italy \\ c Consiglio Nazionale delle Ricerche, Istituto di Biofisica, Via Ugo La Malfa 136, Palermo, Italy
}

\section{A R T I C L E I N F O}

\section{Article history:}

Received 5 July 2013

Received in revised form 25 November 2013

Accepted 9 December 2013

Available online 29 December 2013

\section{Keywords:}

Glycation

Albumin

Protein aggregation

Spectroscopy

Light scattering

Metal

\begin{abstract}
A B S T R A C T
Background: Metal ions such as copper or zinc are involved in the development of neurodegenerative pathologies and metabolic diseases such as diabetes mellitus. Albumin structure and functions are impaired following metaland glucose-mediated oxidative alterations. The aim of this study was to elucidate effects of $\mathrm{Cu}$ (II) and $\mathrm{Zn}$ (II) ions on glucose-induced modifications in albumin by focusing on glycation, aggregation, oxidation and functional aspects.

Methods: Aggregation and conformational changes in albumin were monitored by spectroscopy, fluorescence and microscopy techniques. Biochemical assays such as carbonyl, thiol groups, albumin-bound $\mathrm{Cu}$, fructosamine and amine group measurements were used. Cellular assays were used to gain functional information concerning antioxidant activity of oxidized albumins.

Results: Both metals promoted inhibition of albumin glycation associated with an enhanced aggregation and oxidation process. Metal ions gave rise to the formation of $\beta$-amyloid type aggregates in albumin exhibiting impaired antioxidant properties and toxic activity to murine microglia cells (BV2). The differential efficiency of both metal ions to inhibit albumin glycation, to promote aggregation and to affect cellular physiology is compared. Conclusions and general significance: Considering the key role of oxidized protein in pathology complications, glycation-mediated and metal ion-induced impairment of albumin properties might be important parameters to be followed and fought.
\end{abstract}

(c) 2014 Elsevier B.V. All rights reserved.

\section{Introduction}

Protein alterations represent a growing interest in biophysical and biochemical studies, since they are strongly associated in pathologies such as neurodegenerative and metabolic diseases [1,2].

Glycation, also known as the Maillard reaction, is a slow nonenzymatic reaction that initially involves attachment of glucose or derivatives with free amine groups of protein to form reversibly a Schiff base product, leading to the formation of stable fructosamine residue

Abbreviations: AFM, atomic force microscopy; AGE, advanced glycated end product; $\mathrm{BSA}$, bovine serum albumin; IncBSA, bovine serum albumin incubated at $37^{\circ} \mathrm{C}$; MES, 2(N-morpholino) ethane sulfonic acid; PAGE, polyacrylamide gel electrophoresis; PBS, phosphate buffered saline; FTIR, Fourier Transform InfraRed; ThT, Thioflavin-T

* Correspondence to: G. Navarra, DiFC Università di Palermo, Via Archirafi 36, 90123 Palermo, Italy. Fax: + 390916162461.

** Correspondence to: P. Rondeau, GEICO, 15 Av René Cassin, France. Fax: +262 26293 8237.

E-mail addresses: giovanna.navarra@unipa.it (G. Navarra), rophil@univ-reunion.fr (P. Rondeau).

1 These two authors contributed equally to this work and should be considered co-first authors. (ketoamine) following Amadori rearrangement [3]. Further oxidation and rearrangement of these early stage glycation products irreversibly give rise to advanced glycated end products (AGE) [4]. The glycation process is often associated with oxidative phenomenon, called "glycoxidation", which occurs when oxidative reactions affect the early stage glycation products [5].

Protein glycation and aggregation phenomenon are closely linked since common structural and functional properties are shared by amyloid aggregate type proteins and glycated proteins. Main cellular receptors for AGEs, including RAGE, CD36, MSR-A and MSR-B, are thought to be also primary transporters of amyloid type peptides [6,7]. Besides, protein glycation process could induce the formation of several types of aggregates such as globular forms or amyloid fibrils [8-10]. Terminal glycation products are well known to be closely involved in neurodegenerative diseases by promoting amyloid deposit in brain [11]. In addition, protein aggregates can impair insulin secretion in type II diabetes mellitus and indirectly promote glycation process of main circulatory proteins [12].

In these pathologies, metal ions (mainly copper, iron and zinc) are found to be highly concentrated within the core and periphery of 
amyloid senile plaque and also in the cortical tissue of the brain $[13,14]$ Besides, high amount of metal ions can be related to diabetes mellitus and neurological disorders [15]. If the role of these ions has not been fully clarified in vivo, several evidences suggest an inhibitor or promoting action of these metal ions in the aggregation process depending on the metal/protein ratio and the metal-ion binding mode. Previous studies from our group showed a differential effect of $\mathrm{Cu}(\mathrm{II})$ and $\mathrm{Zn}$ (II) ions in promoting bovine serum albumin or $\beta$-lactoglobulin aggregation [16,17].

Metal ions may be present during protein glycation process and metal-catalyzed oxidation reactions have several intersections with post-translational protein modification induced by glucose. Metal ionmediated glucose autoxidation leads to the formation of high reactive carbonyl compounds [18]. Other studies reported a promoting role of metal ions (ferric $\mathrm{Fe}^{3+}$ and cupric $\mathrm{Cu}^{2+}$ ) in $\alpha$-oxoaldehyde formation from early glycation products or Amadori products [19,20]. In organisms, redox-active metals are transported by proteins. Among proteins which could sequester metal in non-reactive forms, human serum albumin represents the main target protein for glycoxidation. This plasma protein could serve as a circulating depot for many drugs and also metal ions [21,22]. In parallel, albumin is sustainably and continually exposed to oxidative stresses impairing its beneficial properties [23].

Glycation of serum albumin has been widely studied in recent years and the bovine form of albumin (BSA) constitutes the most common molecular model used in glycation research field. Even if albumin is well-known to bind various cationic metals, no data are available on the effect of these metals on albumin glycation. In order to clarify the potential roles of metal on albumin glycation, we focused our study on two metal ions: copper (II) and zinc (II). The glycation process of albumin in the presence or absence of metal was monitored by using biophysical (infrared and fluorescence spectroscopy, AFM microscopy) and biochemical (colorimetric and enzymatic assays) techniques. The impact of metal ions on albumin functionality and cellular cytotoxicity was also investigated.

\section{Materials and methods}

\subsection{Materials}

Non-recombinant bovine serum albumin (BSA) (cat\# A9647), $\mathrm{CuCl}_{2}, \mathrm{ZnCl}_{2}$ and D-(+)-Glucose were from Sigma. AGE (BSAG samples) were prepared as previously described [24] by incubating filtered solutions of $0.4 \mathrm{mM}$ BSA and $100 \mathrm{mM}$ of glucose in MES (4-morpholineethanesulfonic acid) buffer ( $\mathrm{pH}$ 7.2), under sterile conditions and nitrogen gas in capped vials at $37^{\circ} \mathrm{C}$ for seven weeks. During this preparation, solution of $1 \mathrm{mM}$ or $3 \mathrm{mM}$ of copper $\left(\mathrm{CuCl}_{2}\right)$ or zinc $\left(\mathrm{ZnCl}_{2}\right)$ ions could be added. The proteins were dialyzed against MES buffer, pH 7.2 and stored at $-20{ }^{\circ} \mathrm{C}$. For FTIR absorption measurements, samples were washed with MES, $\mathrm{pH}$ 7.2, prepared in $\mathrm{D}_{2} \mathrm{O}$ before the measurements.

\subsection{Absorption and fluorescence measurements}

Samples were diluted 1:60 with buffer ( $6.6 \mu \mathrm{M}$ BSA). UV/Vis absorption measurements were carried out on UV-2401PC Shimadzu spectrophotometer to monitor protein concentration at $280 \mathrm{~nm}$. The calculated molar absorptivity for bovine serum albumin is $46,824 \mathrm{M}^{-1} . \mathrm{cm}^{-1}$ at $278 \mathrm{~nm}$. Glycophore absorbance was measured at $340 \mathrm{~nm}$. Spectra were corrected for scattering contribution, and normalized to metal ion absorption and to protein concentration.

Tryptophan, glycophore and Thioflavin-T fluorescence emissions were measured on our preparations (Jasco FP-6500). The tryptophan emission spectra were determined in the $280-500 \mathrm{~nm}$ range $(270 \mathrm{~nm}$ excitation). AGE-related modifications were determined by measuring glycophore fluorescence at $425 \mathrm{~nm}$ under excitation at $345 \mathrm{~nm}$.
Fluorescence emission of Thioflavin-T was determined at $500 \mathrm{~nm}$ with an excitation at $430 \mathrm{~nm}$.

\subsection{FTIR absorption measurements}

IR spectra were recorded by a Bruker Vertex 70 spectrometer, equipped with a MIR global light source (i.e. U-shaped silicon carbide piece). The spectral resolution was $2 \mathrm{~cm}^{-1}$ and the total number of scans for each spectrum was 100 . All samples were placed between two $\mathrm{CaF}_{2}$ windows, with a $0.05 \mathrm{~mm}$ Teflon spacer. The investigated infrared zone is the region of the Amide I. Amide I band is due to an out of phase combination of the $\mathrm{C}=\mathrm{O}$ and $\mathrm{C}-\mathrm{N}$ stretching modes of amide groups. $\mathrm{D}_{2} \mathrm{O}$ solutions were used in BSA samples to avoid the spectral overlaps between Amide I band and strong absorption band of water at $1640 \mathrm{~cm}^{-1}$. The main component in the Amide I region of BSA infrared absorption is located at about $1650 \mathrm{~cm}^{-1}$ and it is assigned to $\alpha$-helices, the component at about $1680 \mathrm{~cm}^{-1}$ is assigned to $\beta$-turns, and the component at $1635 \mathrm{~cm}^{-1}$ is assigned to intra-molecular $\beta$-sheets.

\subsection{Atomic force microscopy}

Small aliquot $(30 \mu \mathrm{l})$ of protein solution was loaded on freshly cleaved mica. The samples were dried overnight under nitrogen flux and imaged. The instrument used for the AFM measurements in tapping mode was a Veeco MultiMode V Scanning Probe Microscope. Etchedsilicon probes with Al-coating on detector side having a pyramidalshape tip with a nominal curvature $<10 \mathrm{~nm}$ were used. During scanning, the $125 \pm 10 \mu \mathrm{m}$ long cantilevers, with a nominal spring constant in the range of $40 \mathrm{~N} / \mathrm{m}$, oscillated at its resonance frequency (330 kHz). Height, phase and amplitude error images were collected by capturing $512 \times 512$ points in each scan, and the scan rate was maintained below 1 line per second. The worsening of the tips was monitored by using a test pattern before and after every measurement session.

\subsection{Biochemical characterizations}

Fructosamine was determined using the method developed by Johnson et al. [25] with the nitroblue tetrazolium (NBT) reagent and following a protocol described in a previous study [26]. The results are expressed as mmol/l of 1-deoxy-1-morpholinofructose (DMF), which is a synthetic ketoamine used as a primary standard.

TNBS (2, 4, 6-trinitrobenzenesulfonic acid) assay is a sensitive method for determining the primary free amino groups in proteins [27] and was described in a previous study by our group [28]. Various concentrations of L-glycine (10 to $200 \mathrm{nmol}$ ) were used as standards.

Thiol groups in native, modified albumin were measured by Ellman's assay using 5, 5'-dithiobis, 2-nitrobenzoic acid (DTNB) [29] as described previously [24]. A standard curve was performed for each assay and used various concentrations of L-cysteine (10 to $100 \mathrm{nmol}$ ) (Sigma). The content of thiol groups for each BSA sample was measured in duplicate on two different quantities of BSA by reading the absorbance at $412 \mathrm{~nm}$. Results were expressed as the number of free $-\mathrm{SH}$ groups per mol of BSA. Aggregative modifications of glycated albumin samples in the presence or absence of metal were analyzed by native and SDS-Polyacrylamide Gels ( $12 \%$ of acrylamide) and stained by Coomassie blue according to Laemmli's method [30]. Level of carbonylation of proteins was determined by spectrophotometric assay based on recognition of proteinbound DNPH in carbonylated proteins with an anti-DNP antibody [31]. $200 \mu \mathrm{g}$ of protein lysates was precipitated and suspended with $0.5 \mathrm{ml}$ of DNPH solution $(0.2 \%$ in $2 \mathrm{M} \mathrm{HCl})$. Samples were incubated at room temperature for $10 \mathrm{~min}$ and precipitated in 10\% TCA solution before centrifugation (2000 $\mathrm{g}$ for $2 \mathrm{~min}$ ). Extraction of free DNPH from suspended pellets was performed with 3 successive washes with ethanol-ethyl acetate solution (50:50). Then dried protein pellets were dissolved in a $200 \mu$ l guanidine solution ( $6 \mathrm{M}$ in $500 \mathrm{mM} \mathrm{KCl} \mathrm{pH} \mathrm{2.5).} \mathrm{The} \mathrm{absorbance}$ 
of protein samples was measured at $276 \mathrm{~nm}$ and $370 \mathrm{~nm}$ for protein and carbonyl contents, respectively. Carbonyl was expressed as mol carbonyl/mol protein and determined by the following formula:

$\left.\operatorname{Carbonyl}(\mathrm{mol}) / \operatorname{protein}(\mathrm{mol})=\frac{\left(D_{370}\right) * \varepsilon_{M 276 p r o t e i n}}{\left(D O_{276}-0.43 *\left(D O_{370}\right)\right) * \varepsilon_{\text {M370hydrazone }}}\right)$

In previous formula $\varepsilon_{M 276}$ protein equals 46,824 , molar absorptivity of BSA and $\varepsilon_{M 370}$ hydrazone equals 22,000, molar absorptivity of the hydrazone [32].

\subsection{Antioxidant properties of BSA samples}

\subsubsection{KRL or red blood hemolysis test}

Each well of a 96 well-plate was filled with $100 \mu$ (about $1.10^{8}$ erythrocytes, 400,000 cells/ $\mu$ l final concentration) of diluted solution of red blood ( $1 / 10$ in $0.15 \mathrm{M} \mathrm{NaCl})$. Different albumin samples ( $10 \mu \mathrm{M}$ final concentration) were added in triplicates. Hemolysis was started by adding $0.45 \mathrm{M}$ of AAPH in each well. Turbidimetry at $450 \mathrm{~nm}$ was recorded in every $10 \mathrm{~min}$ using a $37{ }^{\circ} \mathrm{C}$-thermostated microplate reader. Results were expressed as $50 \%$ of maximal hemolysis time $\left(\mathrm{HT}_{50}\right.$ in $\left.\mathrm{min}\right)$.

\subsubsection{ORAC test}

The ORAC assay using fluorescein as the fluorescent probe measures the antioxidant capacity of samples to protect fluorescein from AAPHinduced oxidative damage. This method was described in detail in a previous study from our group [33]. The automated ORAC assay was carried out on an Infinite M200 pro spectrofluorometric analyzer (TECAN) at excitation and emission wavelengths of $485 \mathrm{~nm}$ and $530 \mathrm{~nm}$, respectively. The reaction was carried out in phosphate buffer $(75 \mathrm{mM}$, $\mathrm{pH}$ 7.4) containing each albumin sample $(25 \mu \mathrm{l})$ in six replicates and fluorescein solution $(80 \mathrm{nM}, 150 \mu \mathrm{l})$. Trolox solutions at different concentrations $(6-50 \mu \mathrm{M})$ were used as calibration standards. The fluorescence kinetics of fluorescein was followed for $1 \mathrm{~h}$ at $37^{\circ} \mathrm{C}$ after adding automatically AAPH solution ( $150 \mathrm{mM}, 25 \mu \mathrm{l})$ in each well. The fluorescence was recorded every $2 \mathrm{~min}$. Antioxidant curves (fluorescence vs. time) were first normalized to the curve of the blank (phosphate buffer instead of samples or trolox). Then the area under the fluorescence decay curve (AUC) was determined. The antioxidant activity (ORAC value) of samples was calculated by using trolox calibration standards as follows:

ORACvalue $=\frac{(\text { AUCsample }- \text { AUCblank })}{(\text { AUCTrolox }(50 \mu \mathrm{M})-\text { AUCblank })} *([$ Trolox $] /[$ Sample $])$

Results were expressed as Trolox equivalent $(\mu \mathrm{M})$ per $\mu \mathrm{M}$ of BSA.

\subsection{Cell culture of BV2 microglia cells}

Mouse BV2 microglia cells were cultured in completed DMEM medium (10\% FBS, penicillin $(100 \mathrm{U} / \mathrm{ml})$, streptomycin $(100 \mathrm{U} / \mathrm{ml})$ and L-glutamine $(2 \mathrm{mM})$ ). Cells were grown in a $5 \% \mathrm{CO}_{2}$ incubator at $37^{\circ} \mathrm{C}$. BV2 cells were cultured $24 \mathrm{~h}$ in a 96-well plate (10,000 cells/ well) with $200 \mu \mathrm{l}$ DMEM containing $1 \%$ FBS (for MTT and DCF-DA assays) or in a 6-well plate (300,000 cells/well) with $2 \mathrm{ml}$ DMEM containing $1 \%$ FBS (for direct cells count, TNF- $\alpha$ ELISA and annexin V-FITC and PI staining) and treated with modified albumin samples $(50 \mu \mathrm{M})$ or only MES buffer (control).

\subsection{MTT assay on BV2 cells}

The MTT-assay, using the standard 3-(4,5-dimethylthiazol-2-yl)2,5-diphenyl tetrazolium bromide (Sigma), was chosen to evaluate the effect of modified albumin samples on BV2 cell proliferation [34]. After overnight cell incubation, $20 \mu \mathrm{l}$ of the MTT dye $(5 \mathrm{mg} / \mathrm{ml})$ was added into each well followed by $4 \mathrm{~h}$ of incubation. After discarding media, $150 \mu$ of dimethylsulfoxide (DMSO) was added into each well and plates were agitated in the dark for 30 min to solubilize dark blue formazan crystals. Absorbance was read at $595 \mathrm{~nm}$ wavelength. A well containing medium alone (no cell and no treatment) was used for zeroing absorbance.

\subsection{Viable cell count}

FACScan flow cytometer (Becton-Dickinson) was used for the relative counting of viable BV2 cells. Equal amounts of FITC labeled beads (CaliBRITE FITC-beads, $5 \mu \mathrm{m}$; BD Biosciences) were added to each cell suspension just before the FACS-analysis. An electronic gate was set to count the FITC-labeled beads. All BV2 cell and FITC-bead events were recorded, and when the number of counted FITC-labeled beads reached 2000 , the counting process was stopped. A particular cell population was selected by gating and was identified by its typical location in a FSC v. SSC graph. Results were expressed as the percentage of cells with respect to the control (BV2 treated with BSA).

\subsection{Intracellular ROS formation}

After 24 h of treatment, cells were washed twice with PBS, and incubated with $10 \mu \mathrm{M}$ dichlorofluorescin diacetate (DCFH-DA) during 30 min at $37^{\circ} \mathrm{C}$. Then, cells were washed with PBS and DCF fluorescence was measured at $492 \mathrm{~nm}$ (excitation) and $520 \mathrm{~nm}$ (emission). Fluorescence values were calculated after background subtraction (identical conditions without DCFH-DA) and normalized by cell count. Results were expressed as the percentage of DCF fluorescence with respect to the control.

\subsection{Apoptosis and necrosis}

After treatment BV2 cells were collected, washed with PBS and incubated with $2 \mu \mathrm{g} / \mathrm{ml}$ Annexin V-FITC (BioLegend) and $2 \mu \mathrm{g} / \mathrm{ml} \mathrm{PI} \mathrm{(Sigma)}$ in $100 \mu \mathrm{l}$ binding buffer (BioLegend) for $15 \mathrm{~min}$ at RT and were analyzed using FACScan (BD Biosciences) and CellQuest software. Similarly to the viable cell counting, a particular cell population was selected by gating and was identified by its typical location in a FSC v. SSC graph.

\subsection{IL-6 secretion}

The proinflammatory cytokine IL- 6 secretion in BV2 media after $6 \mathrm{~h}$ of treatment in the presence of modified albumin samples $(20 \mu \mathrm{M})$ was quantified using a Human IL-6 ELISA Kit (eBioscience). Results are expressed in pg secreted IL-6 per mg cellular proteins.

\subsection{Copper binding affinities of albumin}

The level of copper ions bound to albumin can be measured spectrophotometrically using bathocuproinedisulfonic acid (BC, Fluka \#11870) $[35,36]$. The protocol is well described in a previous study [26]. The affinity of albumin for copper was also determined by fluorescence. This method is based on the quenching of albumin fluorescence induced by its interaction with metal [37]. The intrinsic fluorescence of bovine albumin is mainly attributed to the tryptophan residues. Different series of assay solutions were prepared by mixing $10 \mu \mathrm{M}$ of native or modified BSA with copper chloride at concentrations ranging from 5 to $100 \mu \mathrm{M}$. Each solution was incubated for $5 \mathrm{~min}$ at $25{ }^{\circ} \mathrm{C}$ and transferred into a quartz cell. The fluorescence spectra were recorded in the range of 250-500 $\mathrm{nm}$ under excitation at $283 \mathrm{~nm}$. The binding parameters (i.e. the binding constant $\mathrm{K}_{\mathrm{A}}$ and the binding site number $\mathrm{n}$ ) for copper were obtained from the following equation [38]:

$\log \frac{\left(\mathrm{F}_{0}-\mathrm{F}_{\mathrm{C}}\right)}{\mathrm{F}_{\mathrm{C}}}=\log \mathrm{K}_{\mathrm{A}}+\mathrm{n} \log [\mathrm{C}]$ 
where $\mathrm{F}_{0}$ and $\mathrm{F}_{\mathrm{C}}$ are the tryptophan fluorescence intensities in the absence and presence of a copper at concentration [C], respectively, and $\mathrm{K}_{\mathrm{A}}$ is the formation constant of the complex formed between the drug and albumin, expressed as $\mathrm{l} / \mathrm{mol}$.

\subsection{Fluorescence data process and statistical analysis}

For each fluorescence spectrum, the zeroth $\left(\mathrm{M}_{0}\right)$ and the first $\left(\mathrm{M}_{1}\right)$ moments of the spectral distribution A (E) were calculated from the experimental data, after subtracting the tangent to the minima of each band, according to the following formula [39]:

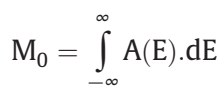

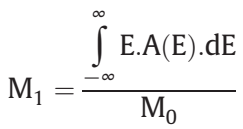

$M_{0}$ measures the integrated intensity and $M_{1}$ is the mean value of the emission energy and measures the position of the band.

Biochemical data were expressed as the mean \pm standard deviation (SD) from a minimum of three experiments. Statistical significances were determined using one-way ANOVA (followed by the Tukey's test).

\section{Results}

Preparations of native (BSA) or glycated albumin (BSAG) incubated with or without $\mathrm{X}$ mM of Zinc ( $\mathrm{Zn})(\mathrm{X}=1$ or 3$)$ were labeled XZnBSA or XZnBSAG. The same nomenclature was used for cooper $(\mathrm{Cu})$-treated samples. Different glycated BSA samples incubated in the presence or absence of metal ions were analyzed in order to determine the impact of metals on albumin structure, conformation, morphology and functionality during protein glycation process.
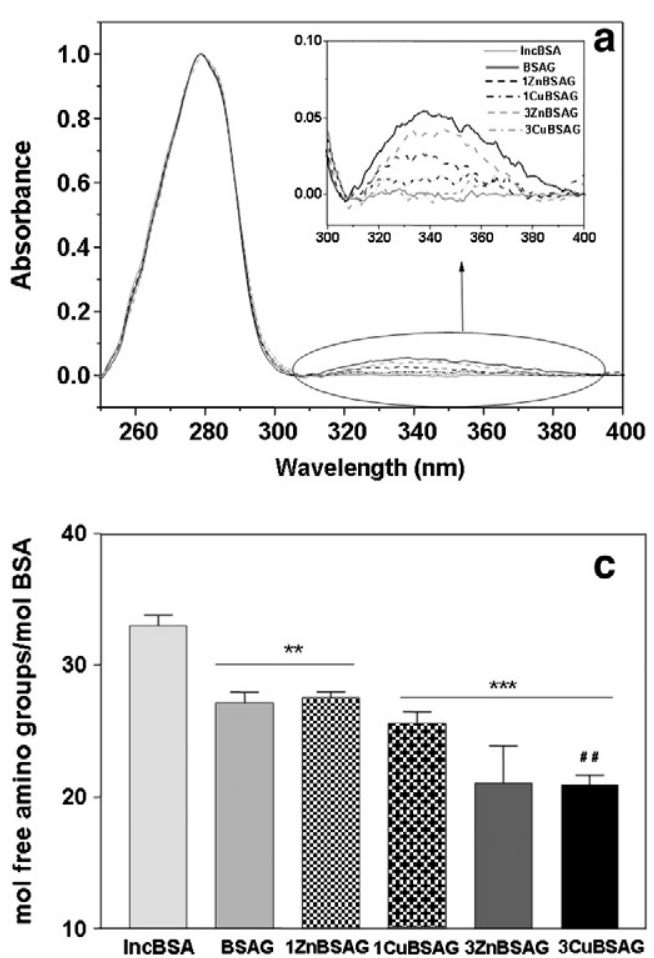

In order to analyze metal ion impact on the protein glycation extent, absorption measurements were performed on all albumin preparations after their incubation for seven weeks at $37^{\circ} \mathrm{C}$. An increase in the absorption band at around $300-380 \mathrm{~nm}$ reflects protein glycation as this spectral range is attributed to the glycophore absorption [40]. On Fig. 1a, we show normalized spectra of samples in order to compare the different glycation extents. Albumins incubated with only glucose (BSAG) or combined with $3 \mathrm{mM} \mathrm{ZnCl}_{2}$ (3ZnBSAG) gave rise to the more glycated samples, while heated albumin (IncBSA) was not characterized by any absorption contribution in this spectral range. In contrary to 1 CuBSAG sample which exhibits a low absorption at about $340 \mathrm{~nm}$ suggesting a low small formation of AGE products, 3CuBSAG sample revealed to have not any glycophore. These data are in accordance with those obtained by fluorescence spectroscopy at $425 \mathrm{~nm}$ emission wavelength (Fig. 1b) and show that the efficiency of glycation process decreased in the presence of copper ions. The presence of zinc, at any concentration, caused a slight decrease in the glycation extent.

Due to their high nucleophile properties, lysine and arginine are the sole residues prone to glycative modification in the presence of glucose [5]. As featured in Fig. 1c, native albumin exhibits about 33 free amine residues. Glycation in the absence or presence of metal ions induced a similar reduction in free amine groups (about $-22 \%$ vs. BSA, $\mathrm{p}<0.01$ ). This reduction was more marked for 3CuBSAG and 3ZnBSAG (about $-36 \%$ vs. BSA, $\mathrm{p}<0.001$ )

In accordance with glycophore data, fructosamine early glycation product was also reduced by the presence of metal ions (Fig. 1d). Fructosamine levels ( $\mathrm{mol} / \mathrm{mol}$ of BSA) were totally reduced by copper and partially by zinc ions in glycated BSA samples.

Structural modifications associated with glycoxidation, in particular the tertiary structure conformation were studied by tryptophan fluorescence measurements. The fluorescence spectra featured in Fig. 2a, show a typical band at about $340 \mathrm{~nm}\left(\lambda_{\mathrm{ex}}=270 \mathrm{~nm}\right)$ attributed to the tryptophan residue fluorescence contribution (Trp 134 and $\operatorname{Trp} 214$ in BSA).
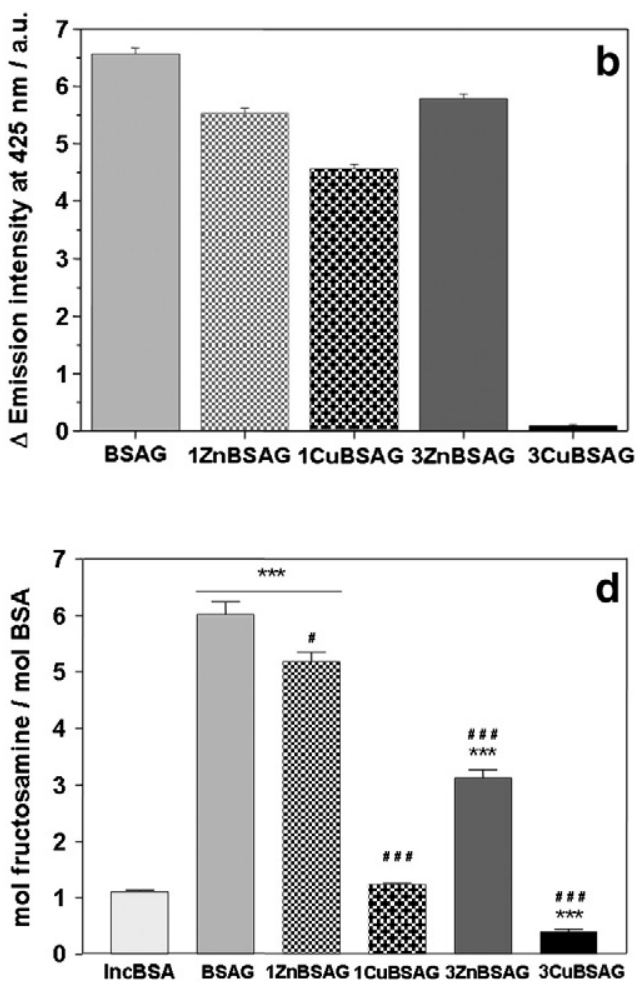

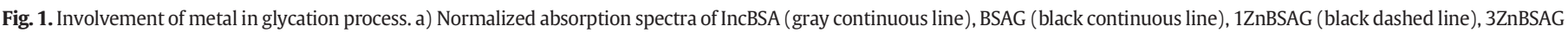

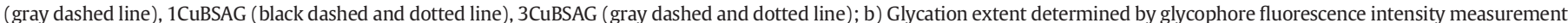

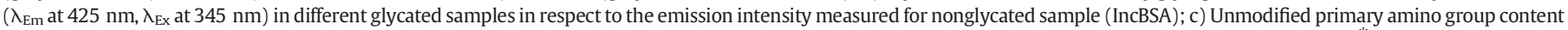

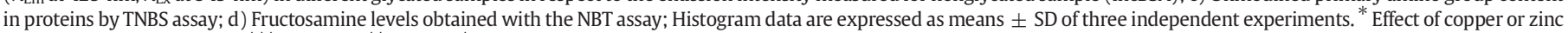
in BSA glycation (vs. BSAG): ${ }^{* * *} \mathrm{p}<0.001,{ }^{* *} \mathrm{p}<0.01,{ }^{*} \mathrm{p}<0.05$. 
In comparison with fluorescence spectra of native (not reported) and of incubated albumin (IncBSA), all modified albumins underwent a differential quenching of tryptophan fluorescence as a consequence of protein incubation with glucose. The decrease in fluorescence suggested different tertiary structure modifications associated with an increase in tryptophan exposure to the solvent amplified in the presence of metals. These results indicated also that conformational changes could be attributed to the simultaneous presence of glucose and metal. The decrease in the intensity may be attributed to BSA glycoxidation, protein partial unfolding and aggregation process, as well. Moreover, the normalized fluorescence spectra featured in Fig. 2b revealed that fluorescence quenching was associated with modification in the position of the maximum band. Indeed, as indicated by the black arrow, a relative blue-shift of tryptophan glycophore (until $10 \mathrm{~nm}$ ) was observed for 1CuBSAG, 3ZnBSAG and 3CuBSAG. A blue-shift is typically due to a less polar environment for both tryptophans and, when associated to a reduction of the band width, it has also been attributed to the formation of more tightly packed structures. Even if both metals have the same chemical valence, they differently affected the tertiary structure. In the presence of $1 \mathrm{mM}$ of zinc (II) no shift was revealed, while copper (II) at the same concentration induced a blue-shift for the fluorescence. Analysis of momentum 1 (M1) relative to the tryptophan emission for different albumin samples is reported in Fig. 2c. Quite similar blue-shifts were observed for IncBSA, BSAG and 1ZnBSAG. Progressively higher M1 values observed for 1CuBSAG, 3ZnBSAG and 3CuBSAG suggested a less polar environment for tryptophan as a consequence of the important conformational changes of protein in the presence of copper(II) or zinc(II) potentially associated with aggregation process [41].

The impact of glucose and metal on the secondary structure of BSA was investigated by FTIR spectroscopy and corresponding spectra in the region of the Amide I band are reported in Fig. 2d. The comparison between native (BSA, circle symbol) with incubated albumins (IncBSA
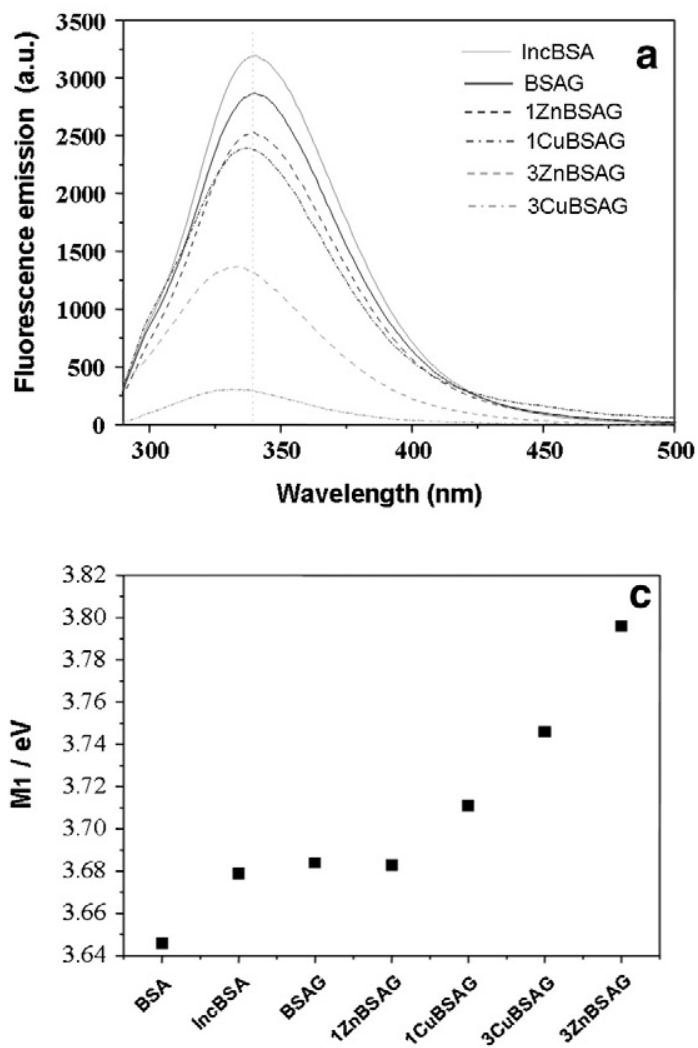

and BSAG, continuous lines) indicated that the sole incubation at $37{ }^{\circ} \mathrm{C}$ induced an increase of intramolecular $\beta$-sheet and $\beta$-turn structures. The similar Amide I profile observed for incubated BSA and BSAG indicated that glycation process in the absence of metal ions did not induce any protein secondary structure modification. This result is in full agreement with previous observations from our group [28]. The presence of metal ions during albumin incubation and glycation mitigated the modifications of the secondary structure caused by heating. Indeed, 1ZnBSAG, 1CuBSAG, 3ZnBSAG (not reported) and native BSA (BSA in Fig. 2d) spectra resulted overlapped. A meaningful difference was noticed for $3 \mathrm{Cu}-\mathrm{BSAG}$ sample. The respective Amide I band featured a marked shoulder at about $1619 \mathrm{~cm}^{-1}$ due to intermolecular $\beta$-sheet structure contribution [41]. This result indicates that, in the presence of glucose and $3 \mathrm{mM}$ of copper (II), the aggregation process of BSA prevailed on its glycation, as attested by the absence of absorption at $340 \mathrm{~nm}$ and glycophore emission at $345 \mathrm{~nm}$.

The aggregative state of the samples was monitored by measuring the Rayleigh scattering peak at $270 \mathrm{~nm}$ excitation wavelength. The saturation of scattered intensities relative to 3ZnBSAG and 3CuBSAG samples observed in Fig. 3a reflected the formation of large aggregates. At lower metal concentrations ( $1 \mathrm{mM}$ ), glycated albumin samples gave similar values of scattered light markedly higher than those obtained for BSAG and BSA. The native and SDS-PAGE electrophoresis profiles of BSA samples corroborated these results (Fig. 3b). The retardation of protein bands was observed in SDS-PAGE profiles for glycated albumin. The increase of apparent molecular masses probably resulted from bound glucose unit and/or aggregative process. The native PAGE profiles showed the disappearance of band relative to the dimeric form of glycated BSA in the presence of copper probably in favor of very high molecular weight oligomers (not visible in the gel).

These results revealed the involvement of both metal ions in the promotion of supramolecular aggregates during albumin incubation. This
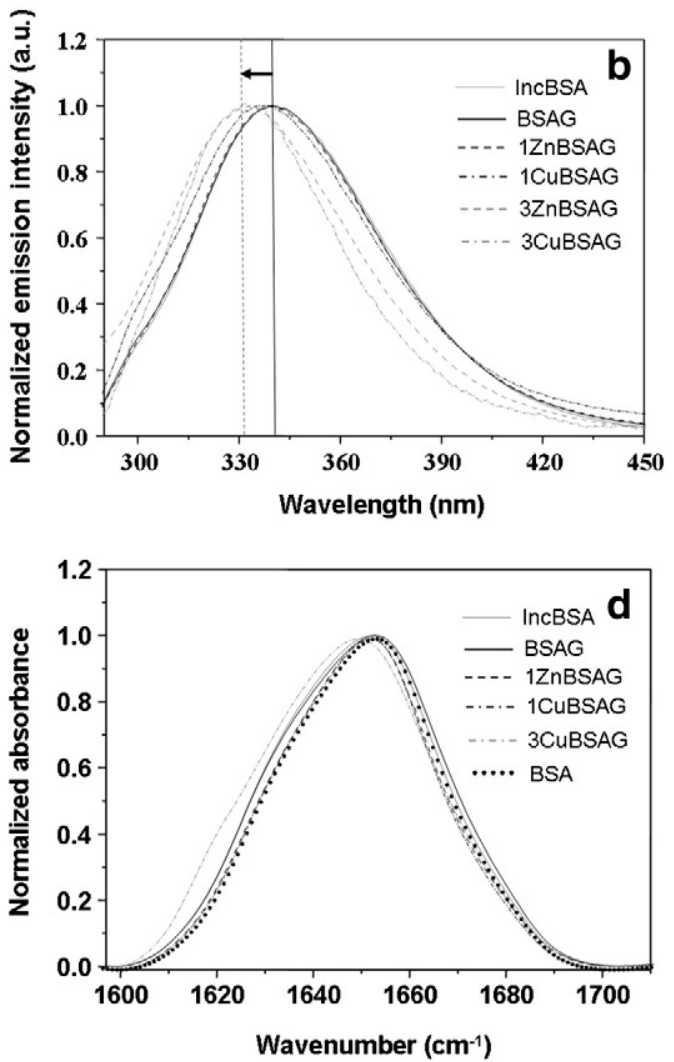

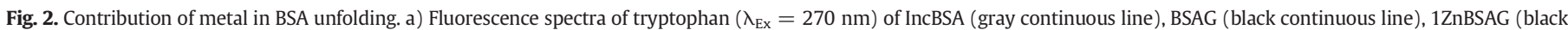

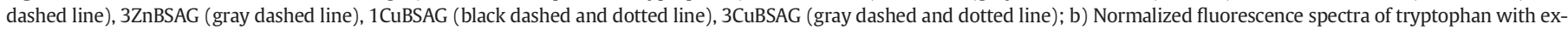

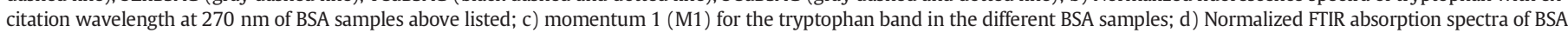
samples above listed and native BSA (circle symbol). All measurements were made at room temperature after heat treatment of the protein solutions at pH 7.2. 

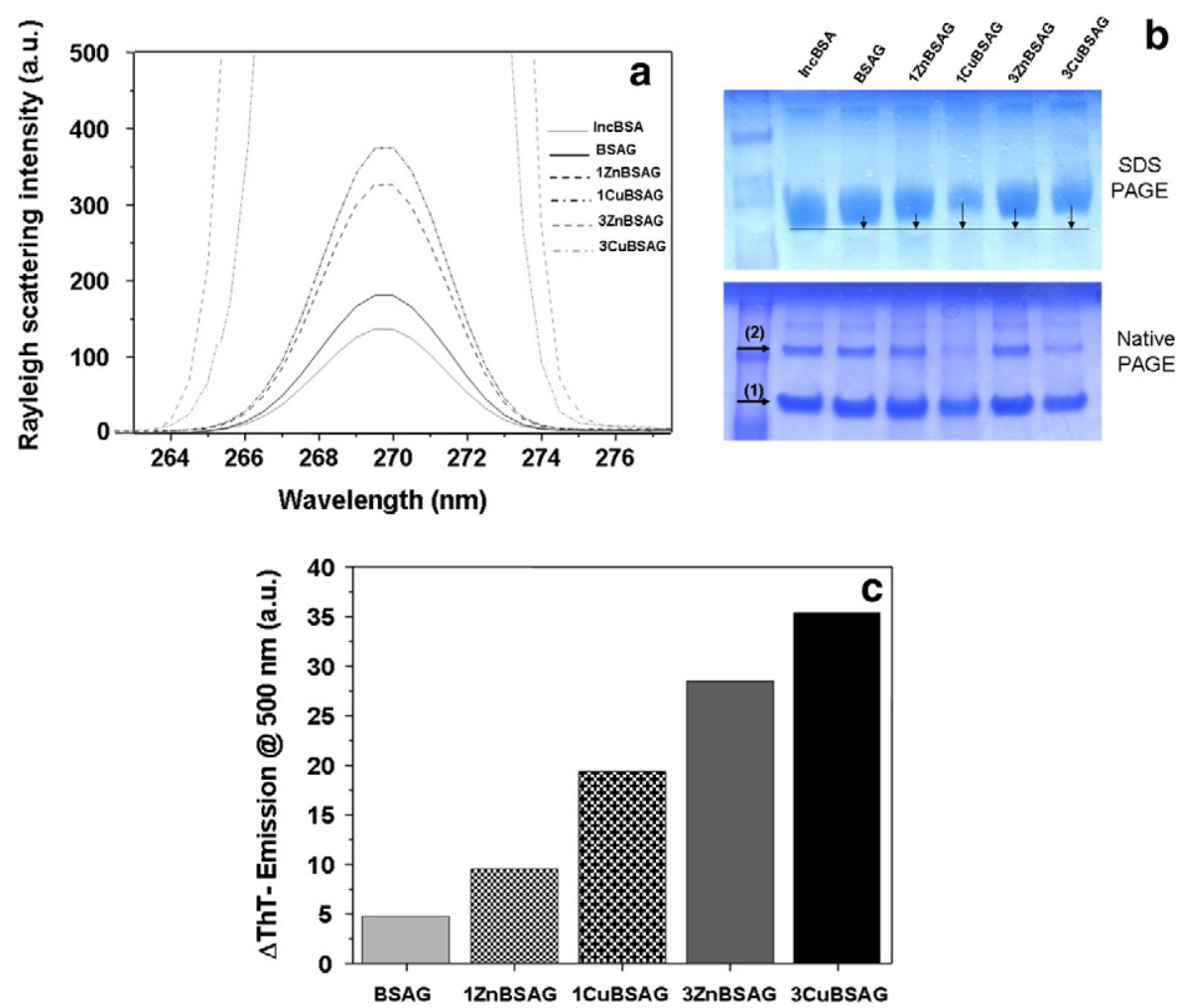

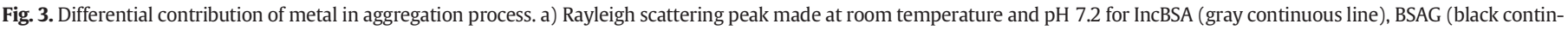

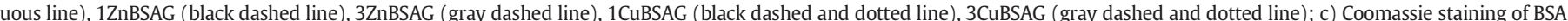

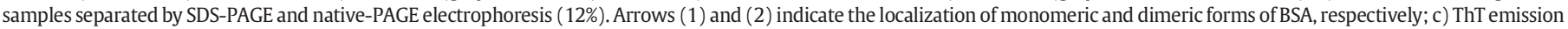
$\left(\lambda_{\mathrm{Em}}\right.$ at $500 \mathrm{~nm}, \lambda_{\mathrm{Ex}}$ at $\left.430 \mathrm{~nm}\right)$ in different glycated samples in respect of the emission intensity measured for not glycated sample (BSA).

experimental evidence is in perfect agreement with previous observations which revealed a higher promoting effect of zinc, compared to copper, in BSA aggregation [16,17].

Measurements of Thioflavin-T (ThT) fluorescence in BSA samples were performed in order to gain further insights into the presence of fibrillar structures (Fig. 3c). The increasing interest on this molecule is revealed by several recent studies dealing on ThT-fibril interaction [42-45]. Emission fluorescence of ThT at $500 \mathrm{~nm}$ progressively increased in the presence of growing concentration of metal ions during albumin incubation with glucose. These results attest that fibrillar
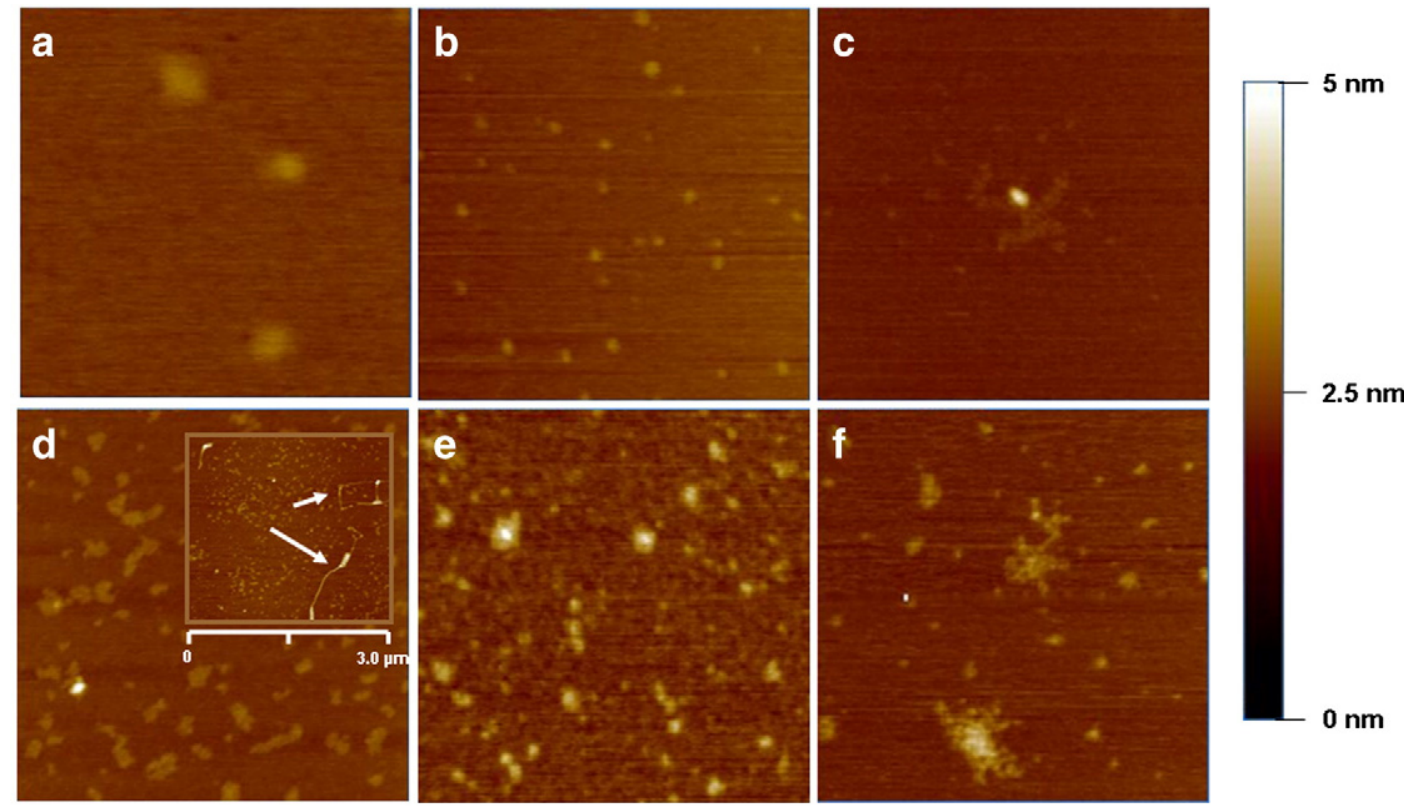

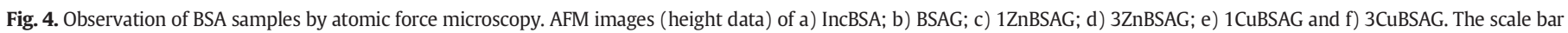
equals $1 \mu \mathrm{m}$. Color scale represents height up to $5 \mathrm{~nm}$. 
structure growth was promoted by metal ions in solution, with a higher efficiency for copper.

Atomic force microscopy (AFM) was used to observe modification in morphology and particle size of glycated protein in the presence and absence of free metal ions during incubation process. As can be seen in Fig. 4a, BSA aggregates exhibited globular morphologies with average 80-100 nm diameter. BSAG sample exhibited lower size (20-40 nm) oligomers probably due to glucose bound to protein molecules preventing the aggregation process (Fig. 4b). This is in agreement with our previous results reporting the effects of glycation on albumin propensity to form aggregates [22]. A shown in Fig. 4c and d, the presence of zinc led to larger aggregate formation. These aggregates, which increased in number and size with metal concentrations, appeared to be globular and amorphous types with the presence of some fibrils long up to few microns (inset of Fig. 4d). This last observation is in accordance with the increase of ThT fluorescence previously shown. Compared to zinc, copper led to the formation of BSA aggregates exhibiting linear and supramolecular morphology (Fig. 4e and f). In agreement with the Rayleigh scattering peak results, BSA aggregates formed during protein glycation in the presence of copper were bigger but less numerous than those formed with zinc.

Glycation process is commonly associated with the phenomenon of oxidation affecting the early stage glycation products. The presence of metal, particularly copper, could amplify protein oxidation. Redox state in BSA samples was investigated by assessing free thiol group content and carbonyl level (Fig. 5a and b). As expected, a significant decrease in free thiol groups was measured following the sole incubation at $37{ }^{\circ} \mathrm{C}$ of IncBSA $(-10 \%$ vs. native BSA, p $<0.01$ ) or the combined incubation and glycation processes for BSAG ( $-34 \%$ vs. native BSA, $\mathrm{p}<0.001$ ). Copper induced a more drastic decrease than zinc probably contributing to an oxidation process to the detriment of glycation. Accordingly to thiol results, levels of protein carbonyls for all albumin samples evidenced a higher oxidation for glycated BSA strongly increased in the presence of copper or $3 \mathrm{mM}$ of zinc.

After determining that glycated albumin could be highly oxidized or aggregated in the presence or absence of metal ions, we investigated the functional integrity and cytotoxicity of these samples. Albumin is a wellknown antioxidant [23]. The intrinsic capacity of albumin to protect erythrocytes from free radical-induced hemolysis was evidenced by a higher hemolysis half-time $\left(\mathrm{HT}_{50}\right)$ for IncBSA ( $+47.3 \%$ vs. MES, $\mathrm{p}<0.05$ ) (Fig. 6a). This protective effect of albumin is a bit strengthened with glycation and in the presence of copper or zinc ions. This increase in BSA antiradical properties could not be ascribed to the sole scavenging properties of Cys 34 which appeared to be highly oxidized in glycated samples. If the strengthened antiradical properties of CuBSAG samples are also noticed in the ORAC test $(+47.8 \%$, vs. BSA, $\mathrm{p}<0.01)$, these properties were rather impaired in the presence of zinc $(-60.5 \%$, vs. BSA, p < 0.001) (Fig. 6b). These conflicting results show that several tests are necessary to assess the overall antioxidant capacity of the protein.

The involvement of microglia in neurodegenerative process of diseases was evidenced in many studies using BV2 microglia cell line $[46,47]$. The effect of BSA samples on BV2 cell viability was evaluated by using MTT assays and FACS. As shown in Fig. 7a, the MTT values decreased significantly after $24 \mathrm{~h}$ incubation with 1 CuBSAG $(-25.4 \%$ vs. BSAG, $\mathrm{p}<0.05)$ and with 3CuBSAG ( $-53.6 \%$ vs. BSAG, $\mathrm{p}<0.001)$. Zn (II) ions gave rise to the formation of highly toxic aggregates in microglia cells only for $3 Z n B S A G(-62.7 \%$ vs. BSAG, $\mathrm{p}<0.001$ ). Similarly to MTT results, the direct cell count showed a significant decrease in the number of viable BV2 cells when incubated in the presence of 3ZnBSAG $(-93.6 \%$ vs. BSAG, $\mathrm{p}<0.01)$ or 3 CuBSAG $(-88.9 \%$ vs. BSAG, $\mathrm{p}<0.01)$.

Analysis of apoptosis and necrosis in BV2 cell using Annexin-V and PI staining showed no increase in apoptotic nor necrotic cells above background levels for BV2 treated with BSA or BSAG (Fig. 8). The presence of copper in BSAG samples resulted in elevated necrosis level in BV2 cells $(+14.3 \%$ for 1 CuBSAG $)$ while early apoptosis $(+35.7 \%)$, late apoptosis $(+29.2 \%)$ and necrosis $(+25 \%)$ were observed for microglia cells treated with 3CuBSAG. In the presence of 3ZnBSAG, BV2 cells were rather apoptotic $(71.3 \%)$ with a majority of early apoptotic cells $(49.5 \%)$ in comparison with the control (BSA). The oxidative state of BSAG samples could play a role in the inhibition in microglia cell proliferation. Intracellular ROS generation was assayed by using DCF-DA fluorescent probe (Fig. 9a). As expected, a significant intracellular ROS increase was observed in microglia treated with CuBSAG $(+97 \%$ vs. BSAG, $\mathrm{p}<0.01$ ) or with 3ZnBSAG $(+151 \%$ vs. BSAG, $\mathrm{p}<0.001)$. If oxidative stress could contribute to affect cellular viability, we can also hypothesize a pro-inflammatory action of our BSA preparations. However, as shown in Fig. 9b, only 1ZnBSAG induced a significant increase in IL-6 secretion by microglia cells.

Our results suggest that copper ions exert inhibitory action on glycation, fibrillar aggregation and oxidation processes. In order to get further insights into copper action, we investigated whether the presence of glucose could impact the affinity of albumin for this metal. Affinity was measured by using a spectroscopic method based on tryptophan fluorescence quenching of albumin. The maximum fluorescence intensity of native albumin at $337 \mathrm{~nm}$, decreased with increasing concentrations of $\mathrm{CuCl}_{2}$ (Fig. S1 see supplementary data) and this is probably because copper ion acts as fluorescent quencher via interactions with the protein. Conversely, zinc ion did not induce any change in quenching of tryptophan fluorescence (data not shown). Hence, this spectroscopic method is not suitable for investigating albumin affinity for zinc. The log plots $\left(\left(\mathrm{F}_{0}-\mathrm{F}_{\mathrm{C}}\right) / \mathrm{F}_{\mathrm{C}}\right)$ of $\mathrm{BSA}_{\mathrm{G} 0}, \mathrm{BSA}_{\mathrm{G} 25}$ and $\mathrm{BSA}_{\mathrm{G} 100}$ versus concentrations $(\log (\mathrm{C}))$ of copper are shown in Fig. 10a. These plots exhibit a good linearity with the correlation coefficients ( $r$ ) above 0.957 (Table 1). The numbers of binding site $n$ and the binding constants $\mathrm{K}_{\mathrm{A}}$, listed in Table 1 were calculated using these lines. The binding site $\mathrm{n}$
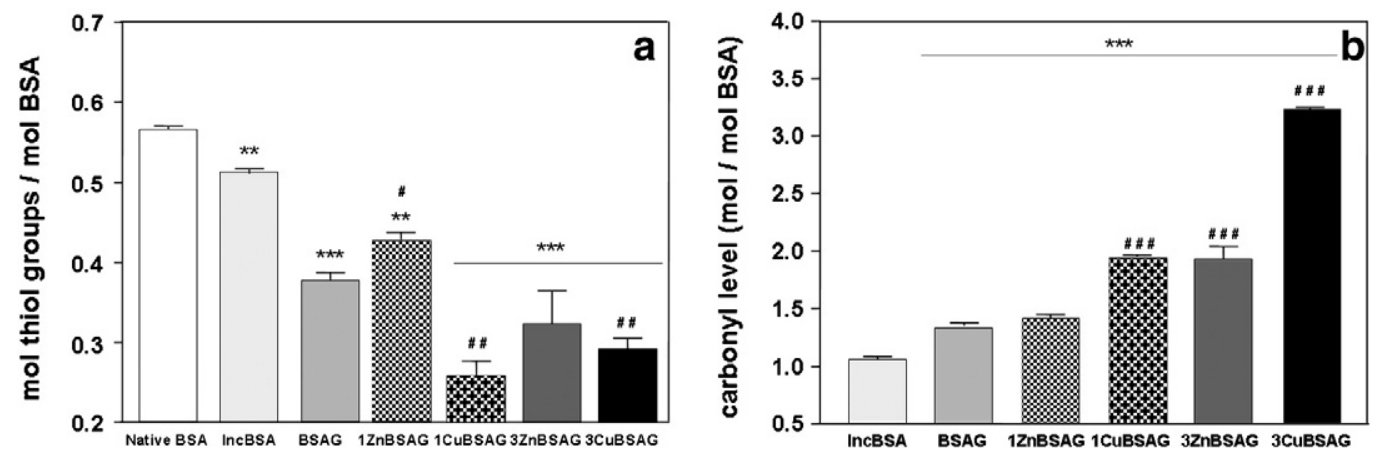

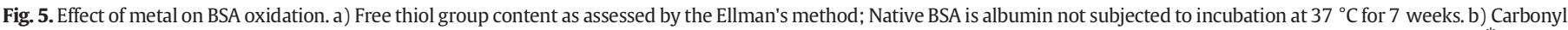

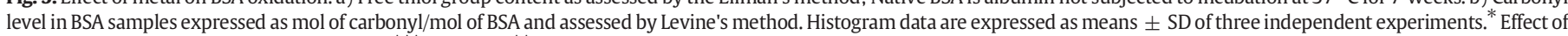
incubation and/or glycation (vs. native BSA): ${ }^{* * *} \mathrm{p}<0.001,{ }^{* *} \mathrm{p}<0.01 .{ }^{\#}$ Effect of copper or zinc in BSA glycation (vs. BSAG): ${ }^{\# \# \#} \mathrm{p}<0.001,{ }^{\# \#} \mathrm{p}<0.01,{ }^{\#} \mathrm{p}<0.05$. 

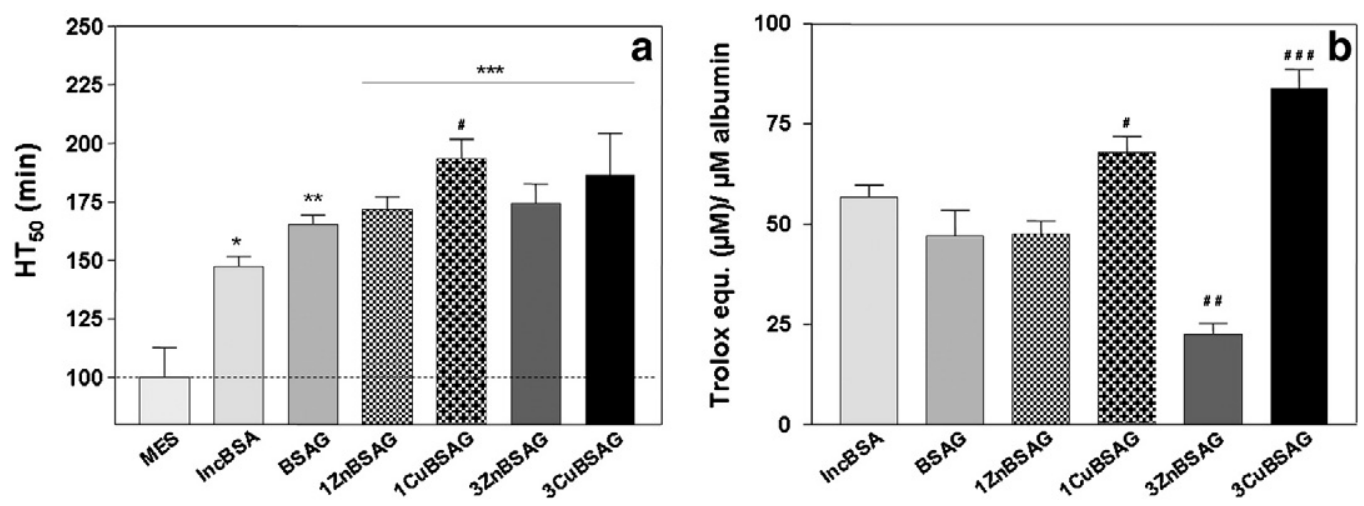

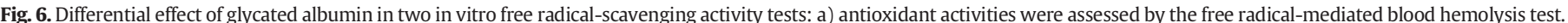

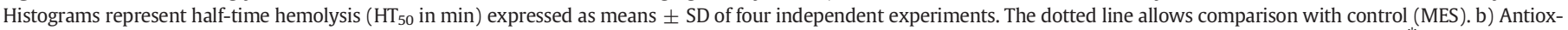

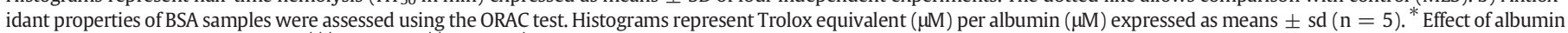
samples in erythrocytes (vs. MES): ${ }^{* * *} \mathrm{p}<0.001,{ }^{* *} \mathrm{p}<0.01,{ }^{*} \mathrm{p}<0.05 .{ }^{\#}$ Effect of copper or zinc in glycated BSA samples $\left(\mathrm{vs}\right.$. BSAG): ${ }^{\# \# \#} \mathrm{p}<0.001,{ }^{\# \#} \mathrm{p}<0.01,{ }^{\#} \mathrm{p}<0.05$.

and $\log \mathrm{K}_{\mathrm{A}}$ correspond to the slope and to the intercept, respectively. BSA affinity for copper increased following protein glycation extent. This suggests a structural modification for albumin incubated with glucose allowing a better binding of metal to the protein. This higher affinity could be explained by the increase in the number of binding sites (from 1.1 to 1.7). Accordingly to this data, the levels of copper bound to BSA samples ( $\mathrm{mol} / \mathrm{mol}$ of BSA), given in Fig. 10b, showed an increase following glycation. Levels of copper bound to the protein incubated for 7 weeks in the presence or absence of glucose were assayed by the same colorimetric method. As shown in Fig. 10c, copper ions were more likely to bind BSA when incubated with glucose.

\section{Discussions}

Serum albumin plays important roles in the transport of many metabolites including trace metals. If specific concentrations of these metals are required for normal physiological functions, abnormal quantity could impact health conditions. For instance, $\mathrm{Zn}$ (II) and $\mathrm{Cu}(\mathrm{II})$ metabolism and concentrations could have a deleterious impact in diabetes development $[15,48]$. $\mathrm{Cu}(\mathrm{II})$, concentrations in blood serum were reported to be significantly higher in NID diabetes mellitus [49]. In addition, treatment with a copper chelating agent could consequently reduce insulin resistance and improve glucose intolerance. In addition, plasma concentration of $\mathrm{Zn}$ (II) appears to be lower in diabetic patients than in healthy subject and a treatment with $\mathrm{Zn}$ (II) exhibited beneficial effects in this disease [50]. Besides, numerous studies evidenced an alteration in zinc metabolism in diabetes [48,51]. For instance, an in vitro study showed that zinc depletion increases insulin vulnerability to free radical-induced oxidation [52]. Circulating albumin glycation and resulting AGE formation represent typical features of diabetes pathology in which high affinity metal ions such as copper or zinc could be involved. These metal ions could potentially affect glycation and AGE formation by taking part in complex formation with amino acids [53]. Thus, the study of $\mathrm{Zn}(\mathrm{II})$ and $\mathrm{Cu}$ (II) impacts on the glycation process of circulating proteins is of utmost importance.

The aim of this study was to assess the role of $\mathrm{Zn}$ (II) and $\mathrm{Cu}(\mathrm{II})$ in the structural modification of BSA by focusing on the glycation, aggregation and oxidation aspects. The main results indicated that both metals exert an inhibiting action in glucose-induced BSA glycation in a concentration dependent manner. Also, copper ions appear to act as a more efficient inhibitor in glycation process than zinc. Indeed, $\mathrm{Cu}(\mathrm{II})$ ions are able to reduce glycation (Amadori products) by a maximum of $94 \%$ while reduction reaches $48 \%$ with $\mathrm{Zn}$ (II) ions. There is no available evidence about the role of metals in albumin glycation in vivo, but a study reported the inhibitory effect of zinc in glycation of other proteins such as hemoglobin [50]. Increase in albumin glycation is commonly associated with a reduction of free amino groups such as lysine or arginine, which represent the main available glycation sites [5]. The results presented here reveal that attenuation of glycation induced by metals is not automatically associated with an increase in free primary amino groups in protein. Modification of these primary amino groups could be attributed to a parallel process including aggregation or oxidation initiated by the presence of both metal and glucose. Indeed, the presence of metal ions differently induces albumin aggregation during glycation. Both $\mathrm{Cu}(\mathrm{II})$ and $\mathrm{Zn}(\mathrm{II})$ promoted the aggregation process during glycation and induced aggregate formation exhibiting different morphologies depending on the nature and concentration of the metal. The important BSA unfolding in the presence of copper/glucose
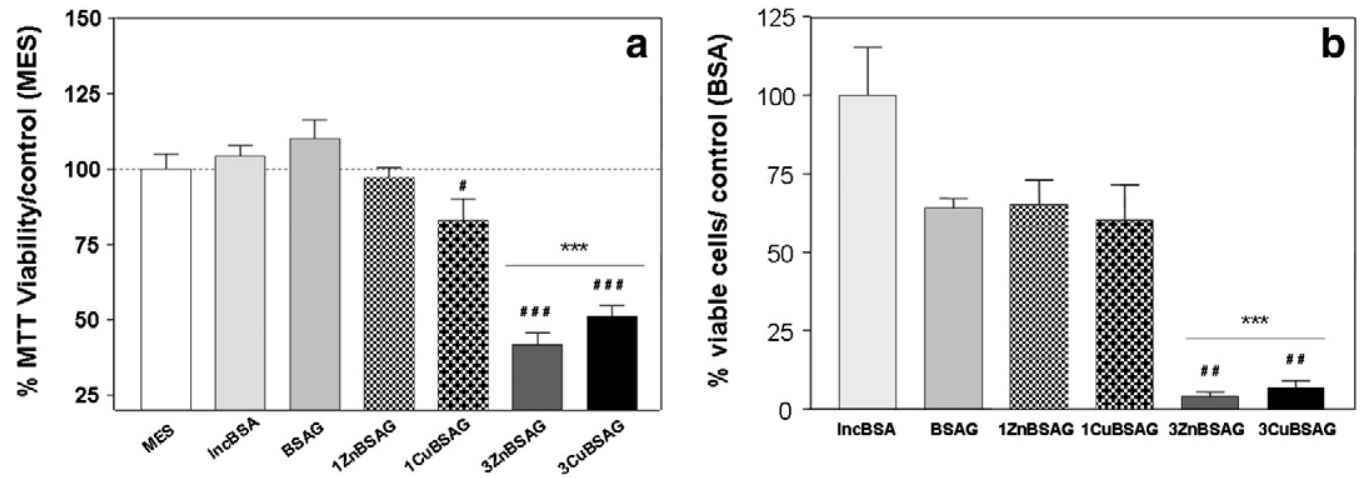

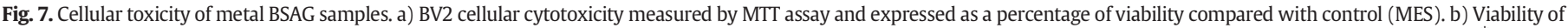

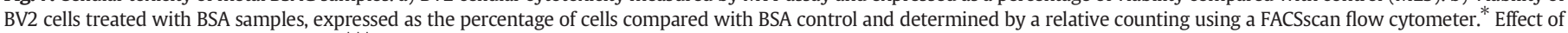
glycation in BV2 cell viability (vs. BSA): ${ }^{* * *} \mathrm{p}<0.001 .{ }^{\#}$ Effect of copper or zinc in glycated BSA sample toxicity $\left(\mathrm{vs}\right.$. BSAG): ${ }^{\# \# \#} \mathrm{p}<0.001,{ }^{\# \#} \mathrm{p}<0.01,{ }^{\#} \mathrm{p}<0.05$. 


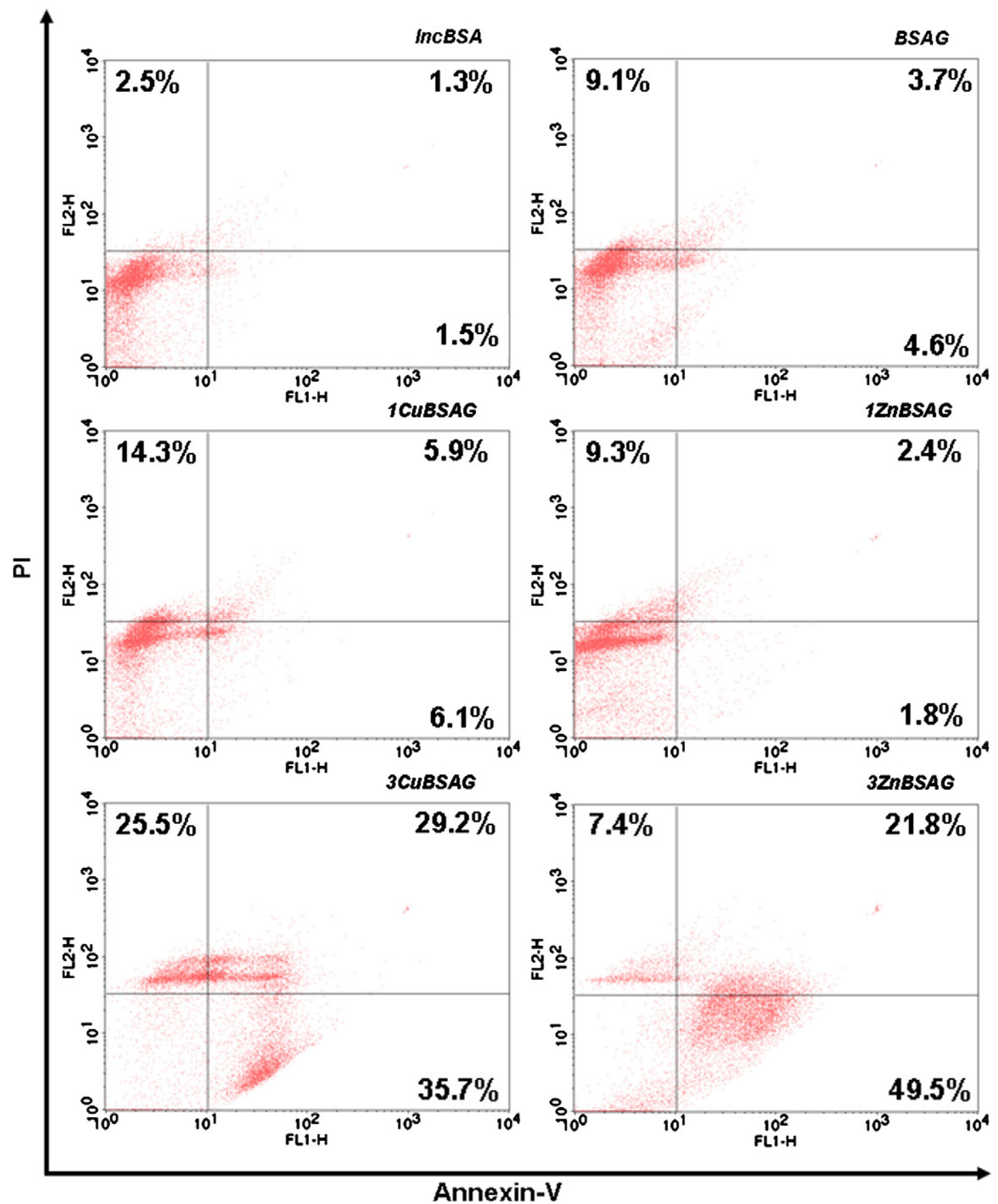

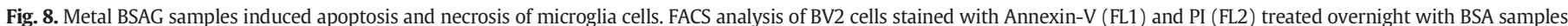

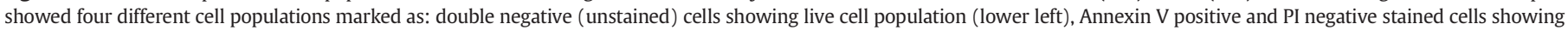

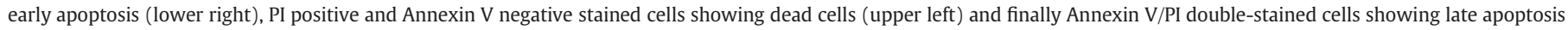
(upper right).

mixture is associated with a secondary structure evolution into intermolecular $\beta$-sheet structure in agreement with the fibrillar morphology and bigger size of aggregates observed in AFM microscopy. The presence of $\beta$-amyloid like fibril in CuBSAG or 3ZnBSAG structures could explain their relative cytotoxicity for microglia cells. Several previous studies have already highlighted this $\beta$-amyloid cytotoxicity of glycated albumin $[8,10]$. We can also notice that the partial conversion of secondary structure from $\alpha$-helix into intramolecular $\beta$-sheets is rather promoted by the sole incubation at $37{ }^{\circ} \mathrm{C}$ than the glycation process. While the presence of $3 \mathrm{mM}$ copper accentuates this conversion also in favor of intermolecular $\beta$-sheet structures, other metal conditions tend to mitigate the effect caused by heating. The tryptophan fluorescence is the main intrinsic probe used here to monitor the denaturation and folding of proteins. However, the quenching of fluorescence could result either from partial unfolding or from protein oxidation promoted by metal ions. As expected, both metals contribute to an enhanced protein oxidation together with greater glycation and/or aggregation processes in the presence of copper. Similarly to glycation and aggregation phenomena, copper ions exhibit potent impact on oxidation process. The enhanced oxidative state was evaluated following the redox status of Cys 34 and the carbonyl levels in albumin. Among amino acids known to form carbonyl derivatives upon metal-catalyzed oxidation, four of them (proline, arginine, lysine and threonine) are particularly prone to oxidation [54]. The particular susceptibility of arginine 

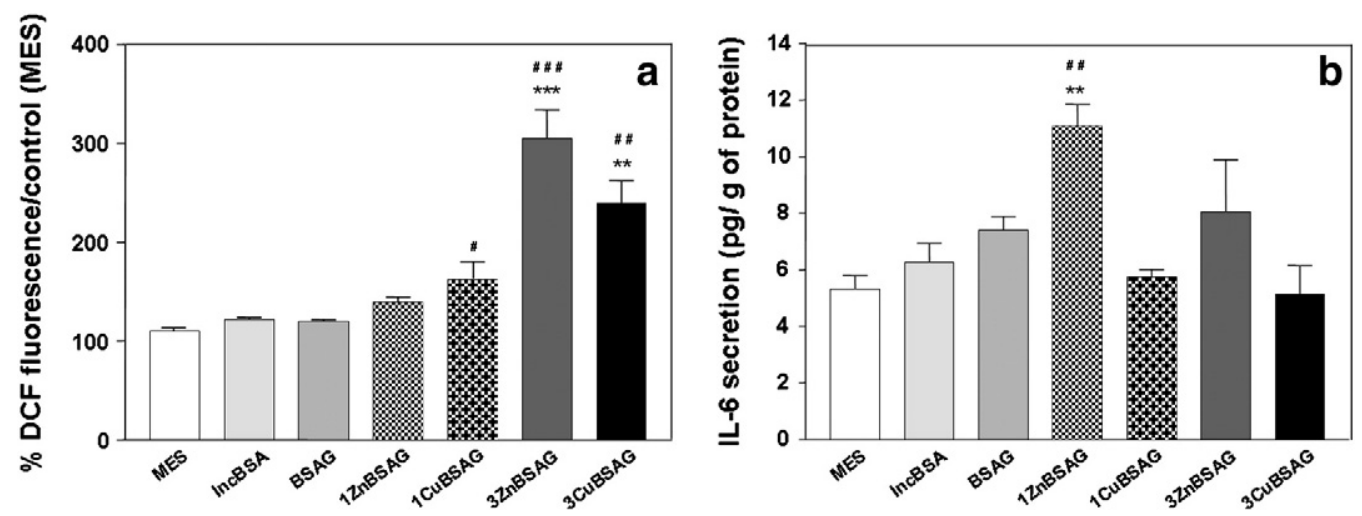

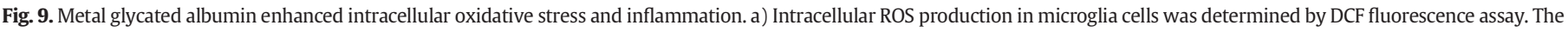

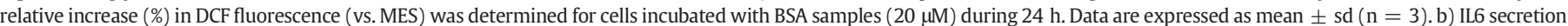

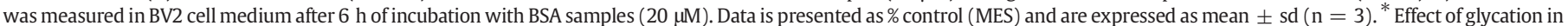
BV2 cells (vs. IncBSA): ${ }^{* * *} \mathrm{p}<0.001,{ }^{* *} \mathrm{p}<0.01$. ${ }^{\#}$ Effect of copper or zinc in glycated BSA samples (vs. BSAG): ${ }^{\# \#} \mathrm{p}<0.001,{ }^{\# \#} \mathrm{p}<0.01$.

and lysine residues to oxidative modification could explain that the decrease in primary amino group level of glycated BSA is not be ascribable to the sole glycation process which is partially or totally inhibited in the presence of $\mathrm{Cu}$ (II) ions. Furthermore, the impact of the sole $\mathrm{Cu}(\mathrm{II})$ ions on primary amino groups was observed (see Fig. S2, supplementary data). The oxidation of these glycation sites by $\mathrm{Cu}(\mathrm{II})$ or $\mathrm{Zn}$ (II) ions could explain the "antiglycative" potential of these metals. However, our findings on the promoting role of Zn on BSA aggregation and oxidation are in partial disagreement with another report stating a reduced $\beta$-aggregation and thiol protection in the Zn-containing glycated BSA

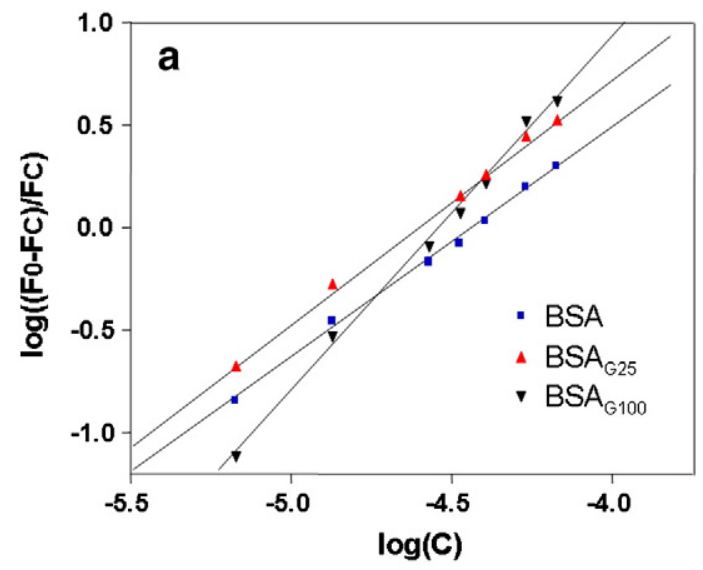

samples [55]. Indeed, on the one hand, in the presence of Zinc(II) less inter and intramolecular $\beta$-structures than IncBSA and BSAG were formed (Fig. 2d). On the other hand, larger supramolecular structures were revealed.

If metal ions have a determining role on albumin structure, they do not drastically affect their antioxidant properties. Both in the red blood cell hemolysis and in ORAC assays, the presence of copper in BSA samples seems to reinforce the free radical trapping capacities of albumin. However, the strengthening in the antiradical capacity of glycated albumin following copper induced-oxidation appears to be in

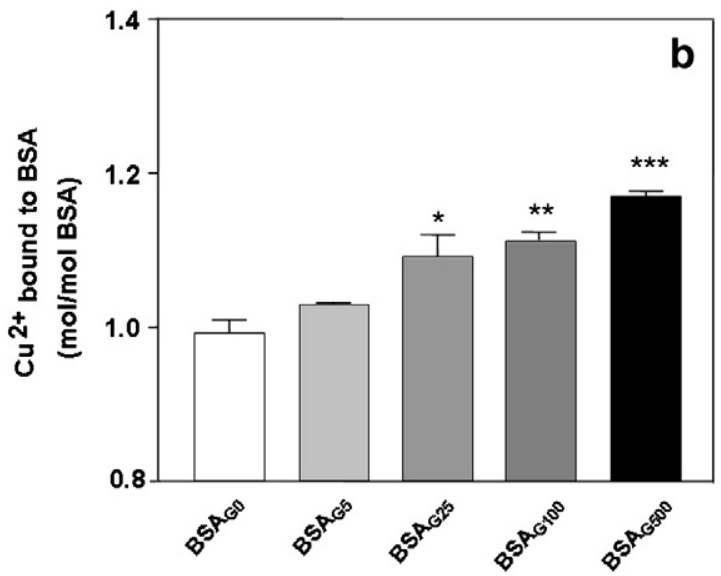

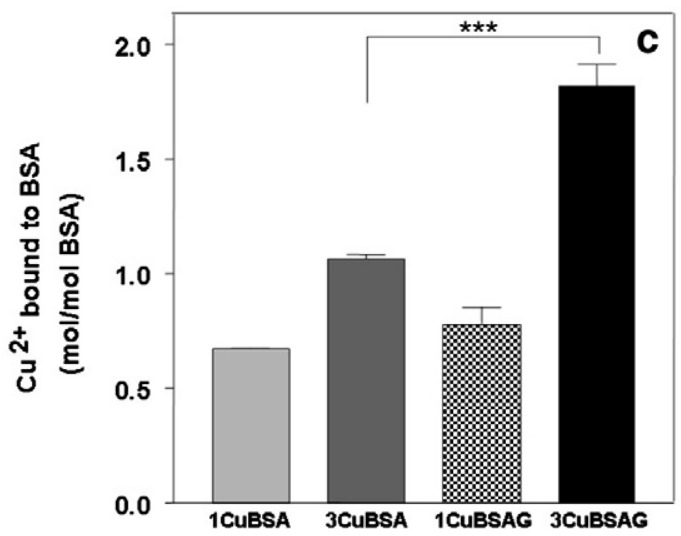

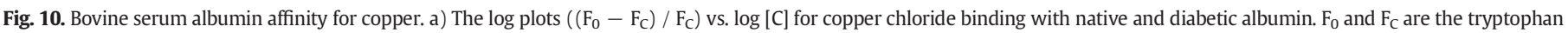

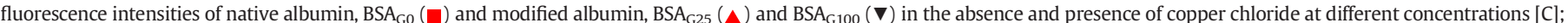

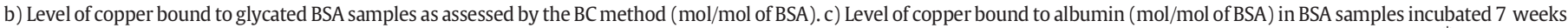

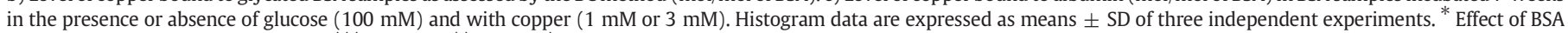
glycation in copper binding (vs. BSA): ${ }^{* * *} \mathrm{p}<0.001,{ }^{* *} \mathrm{p}<0.01,{ }^{*} \mathrm{p}<0.05$. 
Table 1

Binding parameters of copper in native and modified albumin preparations obtained by fluorescence spectroscopy. The binding studies of copper were investigated with $10 \mu \mathrm{M}$ albumin samples at $30{ }^{\circ} \mathrm{C}$. The binding parameters: binding site number ( $\mathrm{n}$ ) and binding constant $\mathrm{K}_{\mathrm{A}}$ were calculated as described in the Materials and methods section.

\begin{tabular}{llll}
\hline & $\begin{array}{l}\text { Binding constant } \mathrm{K}_{\mathrm{A}} \\
(\mathrm{l} / \mathrm{mol}) \text { at } 30{ }^{\circ} \mathrm{C}\end{array}$ & Binding sites (n) & $\begin{array}{l}\text { Correlation } \\
\text { coefficient }(\mathrm{r})\end{array}$ \\
\hline Copper & & & \\
$\mathrm{BSA}_{\mathrm{G} 0}$ & $9.29 \times 10^{4}$ & $1.119 \pm 0.028$ & 0.996 \\
$\mathrm{BSA}_{\mathrm{G} 25}$ & $3.10 \times 10^{5}$ & $1.194 \pm 0.113$ & 0.957 \\
$\mathrm{BSA}_{\mathrm{G} 100}$ & $6.74 \times 10^{7}$ & $1.724 \pm 0.049$ & 0.995 \\
\hline
\end{tabular}

total opposition with previous findings [56]. Even if antioxidant property of albumin seems not to be impaired, there is evidence that the protective role of the protein on cellular system is dramatically altered in the presence of metals, as attested by MTT and FACS results. The cytotoxicity between both metal-modified albumins is found to be quite different with a preferential necrotic pathway observed for murine microglia cells treated with CuBSAG while an apoptotic pathway seems to be rather induced by $3 Z n B S A G$. Moreover, at low metal concentration ( $1 \mathrm{mM})$, only CuBSAG leads to cellular toxicity associated with necrosis, oxidative stress and inflammatory response.

This study gives new evidence that glycation and aggregation should not be in general considered as two competitive processes. For instance, $\mathrm{Zn}$ (II) ions promote the heat-induced aggregation of the protein without completely preventing the glycation process. Conversely, in the presence of $\mathrm{Cu}$ (II) ions, aggregation and glycation appear to be rather competitive processes. If previous studies have demonstrated that aggregation was a process normally associated with glycation [8-10], we have also established that glycated albumin loses its capacity to selfassembly into aggregates following thermal process [28].

In order to understand the several and differential effects of the two investigated metal ions on the glycation, aggregation, oxidation processes and the associated conformational changes, it was necessary to focus on the specific and non-specific affinities of bovine albumin for these metals. We propose schematic models (Fig. 11.) of glycation and metal-induced changes in the structure and the properties of albumin. The presence of metals induces protein oxidation and misfolding contributing to the formation of highly cytotoxic aggregates responsible of microglia activation and death. The differential effect of both metals in glycation and aggregation could also result in the nature of the link between metal and protein which was already reported as different between copper and zinc $[16,17,57]$. Most mammalian albumins, such as HSA or BSA, have four metal binding sites, including N-terminal site, Cys34 residue and site A known to be identical to the Multi-Metal Binding site (MBS) located at the interface of domains I and II [58]. Another metal binding site, called B, whose location remains unknown was characterized for some metals including $\mathrm{Zn}$ (II) [59]. In the metal-binding site A, the imidazole nitrogens of His-67 in domain I and His-247 in domain II could be identified as main ligands for $\mathrm{Zn}$ (II) [60]. If site $\mathrm{A}$ is the preferential site for $\mathrm{Zn}(\mathrm{II})$, it is also a secondary binding site for $\mathrm{Cu}(\mathrm{II})$ [61,62].

Zinc is believed to be chelated by imidazole at histidine residues, but some non-specific binding could also involve cysteine residues [63,64]. Regarding copper ions, serum albumin has one strong binding site in the $\mathrm{N}$-terminal tripeptide (Asp-Ala-His) for $\mathrm{Cu}$ (II), but histidine residues are also suggested as a major ligand, similarly to cysteine [35]. Moreover a previous study showed that both metals could be bound to albumin via histidine-imidazole ring in the MBS/site A [17,60], or in N-terminal site for copper [65]. Indeed, both nitrogen atoms of the 17 histidine residues present in bovine albumin are potential donors for transition metal ions. However, the mode of coordination of both these metals to imidazole is different and does not involve the same nitrogen atom. According to Navarra et al., the first mode of metal binding which involves $\mathrm{Zn}$ (II) ions, can promote intermolecular cross-link, leading to the formation of large aggregates, whereas $\mathrm{Cu}(\mathrm{II})$ ions are more prone to induce intramolecular chelation. This different type of metal coordination could explain why $\mathrm{Zn}(\mathrm{II})$ ions are more likely to promote the aggregation of BSA than $\mathrm{Cu}(\mathrm{II})$ ions in a heat-induced albumin treatment [17]. By contrast to this previous study, the presence of glucose gives rise to

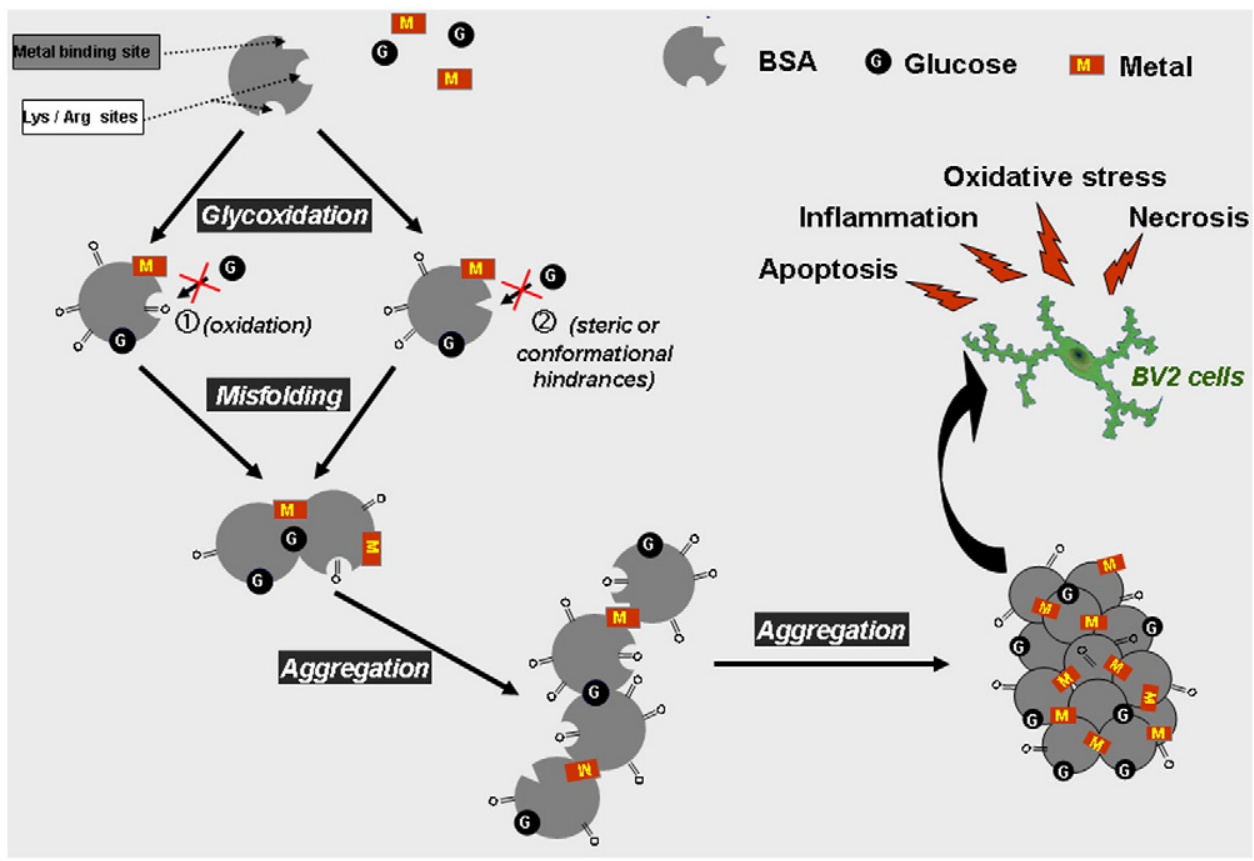

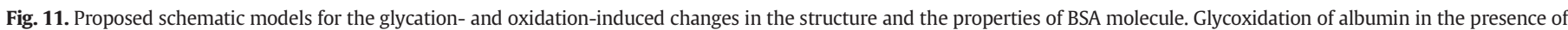

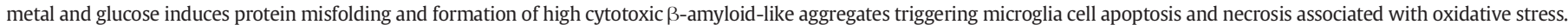

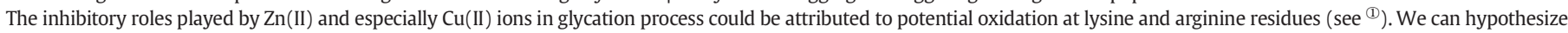

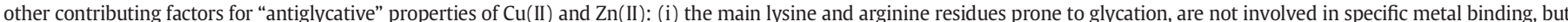

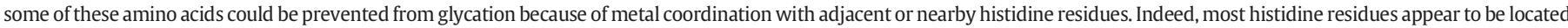

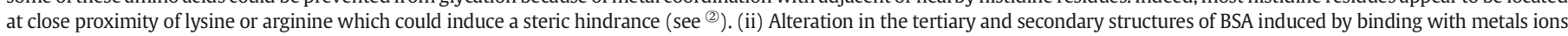
could blunt the capacity of specific glycation sites to react with glucose residues (see ${ }^{(1)}$ ). 
some significant differences in aggregation pathway for BSA. Our findings show that glucose could enhance albumin affinity for copper. Indeed, a higher copper level bound to BSA was observed when glycated or incubated with glucose. This increase in copper affinity could be attributed to a favorable conformational change (i.e. tertiary structure) of albumin induced by glucose.

We previously indicated that the inhibitory roles played by $\mathrm{Zn}$ (II) and especially $\mathrm{Cu}(\mathrm{II})$ ions in glycation process could be attributed to potential oxidation at lysine and arginine residues (see ${ }^{\mathbb{1}}$ in Fig. 11). We can hypothesize other contributing factors for "antiglycative" properties of $\mathrm{Cu}(\mathrm{II})$ and $\mathrm{Zn}(\mathrm{II})$ : (i) the main lysine and arginine residues prone to glycation, are not involved in specific metal binding, but some of these amino acids could be prevented from glycation because of metal coordination with adjacent or nearby histidine residues. Indeed, most histidine residues appear to be located at close vicinity of lysine or arginine which could induce a steric hindrance (see (2) in Fig. 11). (ii) Alteration in the tertiary and secondary structures in BSA induced by binding with metal ions could blunt the capacity of specific glycation sites to react with glucose residues (see ${ }^{1}$ in Fig. 11). The different behavior of zinc and copper and in particular, the inhibiting role played by copper in BSA glycation show that metal ions are noncompletely chelated by the protein through the main binding site and highlights the role of non-specific binding sites in glycation, aggregation and oxidation phenomena.

The main limitation of our study concerns the use of non defatted albumin. The zinc (II) secondary site is functionally linked to the fatty acid binding site and defatted BSA may exhibit a different behavior in both reactivity and spectral features upon glycoxidation. Studies on glycoxidation effects on defatted albumin properties are under progress in our laboratory.

In conclusion, we detailed the involvement of metal ions in the glycation process causing structural modifications in glycated proteins. In particular, we evidenced a marked inhibition of BSA glycation in the presence of copper. We also ascertained that this metal could not be considered as a protective agent regarding its deleterious role in protein oxidation and aggregation by giving rise to cytotoxic aggregates. By contrast, zinc had moderate action on glycation and oxidation processes even if it affected the extent of the aggregation similarly to copper. A distinct polypeptide folding, redox states and metal binding mode of both metal-glycated BSA systems could explain these differences. These findings support the idea that the complexity in the interaction between protein and metal requires further investigation by using in vivo model in order to reach a better understanding of the physiological implication of $\mathrm{Zn}$ and $\mathrm{Cu}$ in albumin properties.

\section{Author contributions}

J.B.V. researched data, contributed discussion, reviewed manuscript. G.N. researched data, wrote, contributed discussion, reviewed manuscript.

M.L. researched data, reviewed manuscript.

E.B. contributed discussion, reviewed and edited manuscript.

V.M. contributed discussion, reviewed manuscript.

P.R. researched data, wrote, reviewed and edited manuscript.

\section{Acknowledgements}

This work was supported by the Ministère de l'Enseignement Supérieur et de la Recherche, the Ministère de l'Outre-Mer, the Conseil Régional de La Réunion, the Université de La Réunion and l'Europe. JBV is supported by a fellowship from the Conseil Régional de La Réunion and l'Europe.

We are grateful to all members of the MBSM group (http://www. fisica.unipa.it/biophysmol/) for continuous stimulating discussions.

\section{Appendix A. Supplementary data}

Supplementary data to this article can be found online at http://dx. doi.org/10.1016/j.bbagen.2013.12.017.

\section{References}

[1] S.B. Prusiner, S.J. DeArmond, Prion diseases and neurodegeneration, Annu. Rev. Neurosci. 17 (1994) 311-339.

[2] M. Brownlee, Advanced protein glycosylation in diabetes and aging, Annu. Rev. Med. 46 (1995) 223-234.

[3] M.P. Cohen, Intervention strategies to prevent pathogenetic effects of glycated albumin, Arch. Biochem. Biophys. 419 (2003) 25-30.

[4] M.P. Cohen, E. Shea, S. Chen, C.W. Shearman, Glycated albumin increases oxidative stress, activates NF-kappa B and extracellular signal-regulated kinase (ERK), and stimulates ERK-dependent transforming growth factor-beta 1 production in macrophage RAW cells, J. Lab. Clin. Med. 141 (2003) 242-249.

[5] P. Rondeau, E. Bourdon, The glycation of albumin: structural and functional impacts, Biochimie 93 (2011) 645-658.

[6] I.S. Coraci, J. Husemann, J.W. Berman, C. Hulette, J.H. Dufour, G.K. Campanella, A.D. Luster, S.C. Silverstein, J.B. El-Khoury, CD36, a class B scavenger receptor, is expressed on microglia in Alzheimer's disease brains and can mediate production of reactive oxygen species in response to beta-amyloid fibrils, Am. J. Pathol. 160 (2002) 101-112.

[7] J.E. Donahue, S.L. Flaherty, C.E. Johanson, J.A. Duncan III, G.D. Silverberg, M.C. Miller, R. Tavares, W. Yang, Q. Wu, E. Sabo, V. Hovanesian, E.G. Stopa, RAGE, LRP-1, and amyloid-beta protein in Alzheimer's disease, Acta Neuropathol. 112 (2006) 405-415.

[8] B. Bouma, L.M. Kroon-Batenburg, Y.P. Wu, B. Brunjes, G. Posthuma, O. Kranenburg, P.G. de Groot, E.E. Voest, M.F. Gebbink, Glycation induces formation of amyloid cross-beta structure in albumin, J. Biol. Chem. 278 (2003) 41810-41819.

[9] N. Sattarahmady, A.A. Moosavi-Movahedi, F. Ahmad, G.H. Hakimelahi, M. Habibi-Rezaei, A.A. Saboury, N. Sheibani, Formation of the molten globule-like state during prolonged glycation of human serum albumin, Biochim. Biophys. Acta 1770 (2007) 933-942

[10] Y. Wei, L. Chen, J. Chen, L. Ge, R. He, Rapid glycation with D-ribose induces globular amyloid-like aggregations of BSA with high cytotoxicity to SH-SY5Y cells, BMC Cell Biol. 10 (2009) 10

[11] M.P. Vitek, K. Bhattacharya, J.M. Glendening, E. Stopa, H. Vlassara, R. Bucala, K. Manogue, A. Cerami, Advanced glycation end products contribute to amyloidosis in Alzheimer disease, Proc. Natl. Acad. Sci. U. S. A. 91 (1994) 4766-4770.

[12] V. Bellotti, P. Mangione, G. Merlini, Review: immunoglobulin light chain amyloidosis-the archetype of structural and pathogenic variability, J. Struct. Biol. 130 (2000) 280-289.

[13] M.A. Lovell, J.D. Robertson, W.J. Teesdale, J.L. Campbell, W.R. Markesbery, Copper, iron and zinc in Alzheimer's disease senile plaques, J. Neurol. Sci. 158 (1998) 47-52.

[14] D. Religa, D. Strozyk, R.A. Cherny, I. Volitakis, V. Haroutunian, B. Winblad, J. Naslund, A.I. Bush, Elevated cortical zinc in Alzheimer disease, Neurology 67 (2006) 69-75.

[15] M.P. Cohen, F.N. Ziyadeh, S. Chen, Amadori-modified glycated serum proteins and accelerated atherosclerosis in diabetes: pathogenic and therapeutic implications, J. Lab. Clin. Med. 147 (2006) 211-219.

[16] G. Navarra, M. Leone, V. Militello, Thermal aggregation of beta-lactoglobulin in presence of metal ions, Biophys. Chem. 131 (2007) 52-61.

[17] G. Navarra, A. Tinti, M. Leone, V. Militello, A. Torreggiani, Influence of metal ions on thermal aggregation of bovine serum albumin: aggregation kinetics and structural changes, J. Inorg. Biochem. 103 (2009) 1729-1738.

[18] S.P. Wolff, R.T. Dean, Glucose autoxidation and protein modification. The potential role of 'autoxidative glycosylation' in diabetes, Biochem. J. 245 (1987) 243-250.

[19] S. Kawakishi, J. Tsunehiro, K. Uchida, Autoxidative degradation of Amadori compounds in the presence of copper ion, Carbohydr. Res. 211 (1991) 167-171.

[20] P.J. Thornalley, A. Langborg, H.S. Minhas, Formation of glyoxal, methylglyoxal and 3-deoxyglucosone in the glycation of proteins by glucose, Biochem. J. 344 (Pt 1) (1999) 109-116.

[21] U. Kragh-Hansen, Structure and ligand binding properties of human serum albumin, Dan. Med. Bull. 37 (1990) 57-84.

[22] T.J. Peters, All About Albumin - Biochemistry, Genetics, and Medical Applications, Academic Press, San Diego, 1996.

[23] M. Roche, P. Rondeau, N.R. Singh, E. Tarnus, E. Bourdon, The antioxidant properties of serum albumin, FEBS Lett. 582 (2008) 1783-1787.

[24] S. Chesne, P. Rondeau, S. Armenta, E. Bourdon, Effects of oxidative modifications induced by the glycation of bovine serum albumin on its structure and on cultured adipose cells, Biochimie 10 (2006) 1467-1477.

[25] R.N. Johnson, P.A. Metcalf, J.R. Baker, Fructosamine: a new approach to the estimation of serum glycosylprotein. An index of diabetic control, Clin. Chim. Acta 127 (1983) 87-95.

[26] A. Guerin-Dubourg, A. Catan, E. Bourdon, P. Rondeau, Structural modifications of human albumin in diabetic context, Diabetes Metab. 38 (2012) 171-178.

[27] S.L. Snyder, P.Z. Sobocinski, An improved 2,4,6-trinitrobenzenesulfonic acid method for the determination of amines, Anal. Biochem. 64 (1975) 284-288.

[28] P. Rondeau, G. Navarra, F. Cacciabaudo, M. Leone, E. Bourdon, V. Militello, Thermal aggregation of glycated bovine serum albumin, Biochim. Biophys. Acta Protein Proteomics 1804 (2010) 789-798.

[29] G.L. Ellman, Tissue sulfhydryl groups, Arch. Biochem. Biophys. 82 (1959) 70-77. 
[30] U.K. Laemmli, Cleavage of structural proteins during the assembly of the head of bacteriophage T4, Nature 227 (1970) 680-685.

[31] R.L. Levine, J.A. Williams, E.R. Stadtman, E. Shacter, Carbonyl assays for determination of oxidatively modified proteins, Methods Enzymol. 233 (1994) 346-357.

[32] R.L. Levine, N. Wehr, J.A. Williams, E.R. Stadtman, E. Shacter, Determination of carbonyl groups in oxidized proteins, Methods Mol. Biol. 99 (2000) 15-24.

[33] J. Baraka-Vidot, A. Guerin-Dubourg, F. Dubois, B. Payet, E. Bourdon, P. Rondeau, New insights into deleterious impacts of in vivo glycation on albumin antioxidant activities, Biochim. Biophys. Acta Gen. Subj. 1830 (2013) 3532-3541.

[34] T. Mosmann, Rapid colorimetric assay for cellular growth and survival: application to proliferation and cytotoxicity assays, J. Immunol. Methods 65 (1983) 55-63.

[35] M.D. Argirova, B.J. Ortwerth, Activation of protein-bound copper ions during early glycation: study on two proteins, Arch. Biochem. Biophys. 420 (2003) $176-184$.

[36] E. Bourdon, N. Loreau, L. Lagrost, D. Blache, Differential effects of cysteine and methionine residues in the antioxidant activity of human serum albumin, Free Radic. Res. 39 (2005) 15-20.

[37] S. Bi, L. Yan, Y. Sun, H. Zhang, Investigation of ketoprofen binding to human serum albumin by spectral methods, Spectrochim. Acta A Mol. Biomol. Spectrosc. 78 (2010) 410-414.

[38] A. Marty, M. Boiret, M. Deumie, How to illustrate ligand-protein binding in a class experiment: an elementary fluorescent assay, J. Chem. Educ. 63 (1986).

[39] M. Leone, S. Agnello, R. Boscaino, M. Cannas, F.M. Gelardi, Conformational disorder in vitreous systems probed by photoluminescence activity in SiO2, Anglais 60 (1999) 11475-11481.

[40] M. Stefek, I. Drozdikova, K. Vajdova, The pyridoindole antioxidant stobadine inhibited glycation-induced absorbance and fluorescence changes in albumin, Acta Diabetol. 33 (1996) 35-40.

[41] P.M. Viallet, T. Vo-Dinh, A.C. Ribou, J. Vigo, J.M. Salmon, Native fluorescence and mag-indo-1-protein interaction as tools for probing unfolding and refolding sequences of the bovine serum albumin subdomain in the presence of guanidine hydrochloride, J. Protein Chem. 19 (2000) 431-439.

[42] M. Groenning, M. Norrman, J.M. Flink, M. van de Weert, J.T. Bukrinsky, G. Schluckebier, S. Frokjaer, Binding mode of Thioflavin T in insulin amyloid fibrils, J. Struct. Biol. 159 (2007) 483-497.

[43] M. Groenning, L. Olsen, M. van de Weert, J.M. Flink, S. Frokjaer, F.S. Jorgensen, Study on the binding of Thioflavin $\mathrm{T}$ to beta-sheet-rich and non-beta-sheet cavities, J. Struct. Biol. 158 (2007) 358-369.

[44] M.R. Krebs, E.H. Bromley, A.M. Donald, The binding of thioflavin-T to amyloid fibrils: localisation and implications, J. Struct. Biol. 149 (2005) 30-37.

[45] R. Khurana, C. Coleman, C. Ionescu-Zanetti, S.A. Carter, V. Krishna, R.K. Grover, R. Roy, S. Singh, Mechanism of thioflavin T binding to amyloid fibrils, J. Struct. Biol. 151 (2005) 229-238.

[46] A. Henn, S. Lund, M. Hedtjarn, A. Schrattenholz, P. Porzgen, M. Leist, The suitability of BV2 cells as alternative model system for primary microglia cultures or for animal experiments examining brain inflammation, ALTEX 26 (2009) 83-94.
[47] B. Liu, J.S. Hong, Role of microglia in inflammation-mediated neurodegenerative diseases: mechanisms and strategies for therapeutic intervention, J. Pharmacol. Exp. Ther. 304 (2003) 1-7.

[48] C. Seneviratne, G.W. Dombi, W. Liu, J.A. Dain, The in vitro glycation of human serum albumin in the presence of Zn(II), J. Inorg. Biochem. 105 (2011) 1548-1554.

[49] A. Tanaka, H. Kaneto, T. Miyatsuka, K. Yamamoto, K. Yoshiuchi, Y. Yamasaki, I. Shimomura, T.-a. Matsuoka, M. Matsuhisa, Role of copper ion in the pathogenesis of type 2 diabetes, Endocr. J. 56 (2009) 699-706.

[50] R.A. Al-Maroof, S.S. Al-Sharbatti, Serum zinc levels in diabetic patients and effect of zinc supplementation on glycemic control of type 2 diabetics, Saudi Med. J. 27 (2006) 344-350.

[51] M.D. Chen, Y.M. Song, P.Y. Lin, Zinc effects on hyperglycemia and hypoleptinemia in streptozotocin-induced diabetic mice, Horm. Metab. Res. 32 (2000) 107-109.

[52] P. Faure, J.L. Lafond, C. Coudray, E. Rossini, S. Halimi, A. Favier, D. Blache, Zinc prevents the structural and functional properties of free radical treated-insulin, Biochim. Biophys. Acta 1209 (1994) 260-264.

[53] D.T. Ramonaityte, M. Kersiene, B. Mockaitiene, The interaction of heavy metals ( $\mathrm{Cu}, \mathrm{Fe}$, and $\mathrm{Zn}$ ) with Maillard reaction products in the lactose-glycine system, Ann. N. Y. Acad. Sci. 1043 (2005) 889.

[54] E.R. Stadtman, Oxidation of free amino acids and amino acid residues in proteins by radiolysis and by metal-catalyzed reactions, Annu. Rev. Biochem. 62 (1993) 797-821

[55] R.S. Tupe, V.V. Agte, Role of zinc along with ascorbic acid and folic acid during long-term in vitro albumin glycation, Br. J. Nutr. 103 (2010) 370-377.

[56] E. Bourdon, N. Loreau, D. Blache, Glucose and free radicals impair the antioxidant properties of serum albumin, FASEB J. 13 (1999) 233-244.

[57] G. Navarra, D. Giacomazza, M. Leone, F. Librizzi, V. Militello, P.L. San Biagio, Thermal aggregation and ion-induced cold-gelation of bovine serum albumin, Eur. Biophys. J. 38 (2009) 437-446.

[58] W. Bal, M. Sokolowska, E. Kurowska, P. Faller, Binding of transition metal ions to albumin: sites, affinities and rates, Biochim. Biophys. Acta 1830 (2013) 5444-5455.

[59] G. Fanali, Y. Cao, P. Ascenzi, M. Fasano, Mn(II) binding to human serum albumin: a (1)H-NMR relaxometric study, J. Inorg. Biochem. 117 (2012) 198-203.

[60] A.J. Stewart, C.A. Blindauer, S. Berezenko, D. Sleep, P.J. Sadler, Interdomain zinc site on human albumin, Proc. Natl. Acad. Sci. U. S. A. 100 (2003) 3701-3706.

[61] W. Bal, J. Christodoulou, P.J. Sadler, A. Tucker, Multi-metal binding site of serum albumin, J. Inorg. Biochem. 70 (1998) 33-39.

[62] P.J. Sadler, J.H. Viles, $1 \mathrm{H}$ and 113)Cd NMR investigations of $\mathrm{Cd}(2+)$ and $\mathrm{Zn}(2+)$ binding sites on serum albumin: competition with $\mathrm{Ca}(2+), \mathrm{Ni}(2+), \mathrm{Cu}(2+)$, and Zn(2+), Inorg. Chem. 35 (1996) 4490-4496.

[63] B. Deng, Y. Wang, P. Zhu, X. Xu, X. Ning, Study of the binding equilibrium between $\mathrm{Zn}$ (II) and HSA by capillary electrophoresis-inductively coupled plasma optical emission spectrometry, Anal. Chim. Acta. 683 (2010) 58-62.

[64] E.L. Giroux, R.I. Henkin, Competition for zinc among serum albumin and amino acids, Biochim. Biophys. Acta Gen. Subj. 273 (1972) 64-72.

[65] C. Hureau, H. Eury, R. Guillot, C. Bijani, S. Sayen, P.L. Solari, E. Guillon, P. Faller, P. Dorlet, X-ray and solution structures of $\mathrm{Cu}(\mathrm{II}) \mathrm{GHK}$ and $\mathrm{Cu}(\mathrm{II})$ DAHK complexes: influence on their redox properties, Chemistry 17 (2011) 10151-10160. 